\title{
Nonlinear Dynamic Analysis for Safety Assessment of Heritage Buildings: Church of Santa Maria de Belém
}

\author{
João Roque ${ }^{1}$; Daniel V. Oliveira ${ }^{2}$; Tiago Miguel Ferreira ${ }^{3}$; and Paulo B. Lourenço ${ }^{4}$
}

\begin{abstract}
Despite the remarkable longevity of heritage constructions, they typically present several structural fragilities inherent to their own material and constructive features. This fact is particularly relevant when seismic loads are concerned, because a very significant portion of such constructions lack adequate seismic resistance and require retrofitting interventions in order to mitigate their vulnerability. However, to guarantee the success of the interventions, the interventions should be carefully selected based on a full understanding of the dynamic response of the building and, particularly, its most vulnerable structural elements. Due to many reasons, the issues associated with this kind of analysis are still difficult to address; therefore, research on this subject should be encouraged. Taking this into account, the church of Santa Maria de Belém, one of the most emblematic buildings of the monastery of Jerónimos complex in Lisbon, is used in this work as a case study to discuss the nonlinear dynamic response of cultural heritage buildings. The nonlinear dynamic behavior of the church was numerically simulated with a three-dimensional (3D) model using artificially generated seismic acceleration time histories, in agreement with seismic hazard scenarios for return periods of 475, 975, and 5,000 years. The dynamic response of the church is discussed and a comparison against results derived from a pushover analysis is also presented. Finally, a modal analysis is presented, estimating the damage level that would be present in the church after the occurrence of such seismic scenarios. DOI: 10.1061/(ASCE)ST.1943-541X.0002437. (c) 2019 American Society of Civil Engineers.
\end{abstract}

\section{Introduction}

Earthquakes continue to represent a serious threat worldwide, particularly in Mediterranean countries in which such events have triggered significant destruction and loss in recent decades. Despite the unpredictable nature of earthquakes, seismic risk assessment should be addressed bearing in mind the main cause of damage, which is related to the inadequate seismic resistance of existing structures, either residential, industrial, or cultural heritage buildings (Maio and Tsionis 2016). As in many other European countries, a large portion of Portuguese cultural heritage is comprised of unreinforced masonry buildings. Despite their remarkable longevity, such buildings lack adequate seismic resistance, calling into question not only their preservation but also the safety of people and goods. In order to change this reality, it is necessary to support the development of new knowledge in this specific field and form a basis for the establishment of more efficient protection measures to safeguard of this valuable heritage (Ferreira et al. 2015b).

The analysis of the structural response of ancient masonry buildings in general (D'Ayala 2013; Lagomarsino and Resemini 2009)

${ }^{1}$ Adjunct Professor, Dept. of Applied Mechanics, Polytechnic Institute of Bragança, 5300 Bragança, Portugal. Email: jroque@ipb.pt

${ }^{2}$ Associate Professor, Dept. of Civil Engineering, Institute of Science and Innovation for Bio-Sustainability, Univ. of Minho, 4800-058 Guimarães, Portugal. Email: danvco@ civil.uminho.pt

${ }^{3}$ Postdoctoral Researcher, Dept. of Civil Engineering, Institute of Science and Innovation for Bio-Sustainability, Univ. of Minho, 4800-058 Guimarães, Portugal (corresponding author). ORCID: https://orcid.org /0000-0001-6454-7927. Email: tmferreira@ civil.uminho.pt

${ }^{4}$ Full Professor, Dept. of Civil Engineering, Institute of Science and Innovation for Bio-Sustainability, Univ. of Minho, 4800-058 Guimarães, Portugal. Email: pbl@civil.uminho.pt

Note. This manuscript was submitted on September 16, 2018; approved on April 2, 2019; published online on September 26, 2019. Discussion period open until February 26, 2020; separate discussions must be submitted for individual papers. This paper is part of the Journal of Structural Engineering, (C) ASCE, ISSN 0733-9445. and of monumental buildings in particular (Betti and Vignoli 2011; Milani and Valente 2015a) is a very challenging task. Their geometry is frequently complex, and the properties and internal structure of their constituting materials are often extremely difficult to define; these conditions necessarily limit the selection of approaches that can be applied (Lourenço 2002; Valente and Milani 2016). Actually, none of the currently applied static analysis techniques (Araujo et al. 2012; Gattulli et al. 2013; Milani 2013; Milani and Venturini 2011, 2013) can be successfully used to assess the seismic safety of monumental buildings.

To help practitioners, the Italian guidelines for cultural heritage (DPCM 2011) suggest the use of a quite rough approach to obtaining the acceleration at collapse. The approach is based on the preassignment of partial failure mechanisms and on the utilization of the kinematic theorem of limit analysis within the assumption of a no-tension material model for masonry. However, such an approach has some evident drawbacks; for instance, it bears the risk of overestimating the horizontal acceleration at failure due to the incorrect identification of failure mechanisms and the geometrical simplifications introduced in the model. Nonlinear static analysis, also known as pushover analysis, represents a current alternative to limit analysis (Betti et al. 2015; Milani and Valente 2015b). However, as is well known, nonlinear static analysis conducted when the global behavior beyond the maximum load-carrying capacity is required cannot be easily carried out using refined finite-element modeling with many two-dimensional (2D) and three-dimensional (3D) elements, as needed for a realistic analysis of masonry churches (Milani and Valente 2015b). Moreover, complex material models are not usually implemented in most of the commercial codes available for standard design. From this, it seems clear that, despite the level of complexity of finite-element analysis, which makes it almost unusable for most practitioners, the limits of the applicability of nonlinear static approaches should be handled with great care.

In this context, this paper aims to contribute to the discussion of the nonlinear dynamic analysis of monumental buildings, using the 


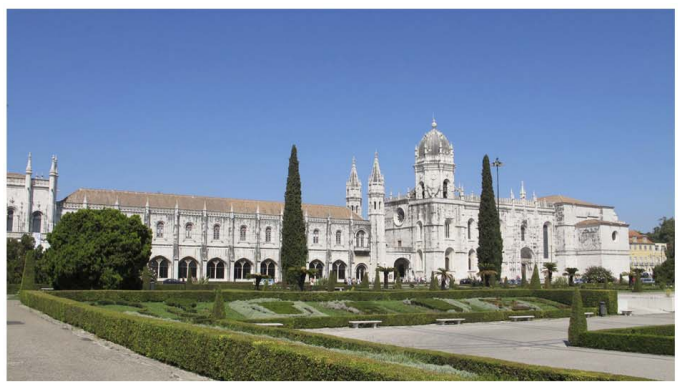

(a)

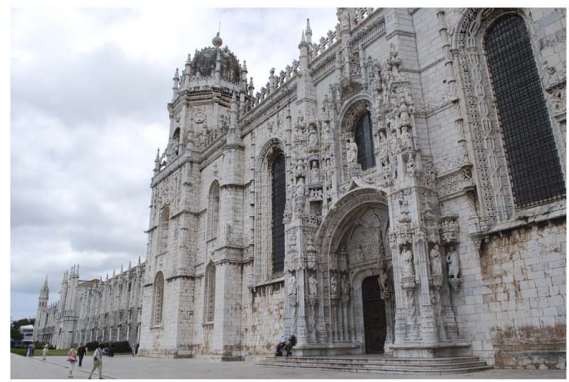

(b)

Fig. 1. Monastery of Jerónimos: (a) external view of the complex; and (b) outer view of the church. (Images by authors.)

church of Santa Maria de Belém (also known as the church of the monastery of Jerónimos) as a case study. Integrated within the monastery of Jerónimos complex, this UNESCO world heritage monument is considered one of the most extraordinary examples of Portuguese architectural heritage. The nonlinear dynamic response of the church was analyzed with a 3D model built in the software DIANA version 10.1, and the results, obtained from artificially generated far-field earthquake records associated with medium- to high-seismic-risk scenarios in Portugal (Carvalho et al. 2009) for increasing return periods $(475,975$, and 5,000 years), are comprehensively discussed in this paper. The analysis is focused on the critical elements of the structure, previously identified in (Masciotta et al. 2016), whose performance is assessed on the basis of several structural outputs, namely bending moment-curvature diagrams and stress-strain curves. In addition, the global response of the church is evaluated in terms of base shear, including the outcomes from the pushover analysis. Finally, a postaction modal analysis is presented, estimating the level of modal damage present in the church.

It is important to stress that, although the structural behavior of the church of Santa Maria de Belém has already been addressed in some past research, namely in Lourenço et al. (2007), Ramos et al. (2010), and Masciotta et al. (2016), no previous research focused on the nonlinear dynamic response of the monument; therefore, this paper represents an important contribution to the understanding of its seismic behavior. In addition, taking into account that very few time history analyses have been used to date to assess the seismic performance of monumental constructions (which still remains a true challenge), this work is also intended to serve as a representative example of how similar issues in analog heritage structures can be addressed.

\section{Church of Santa Maria de Belém}

Built during the 16th century (started in January 1501 and finished about 100 years later), the church of Santa Maria de Belém belongs to the monastery of Jerónimos complex, one of the most notable examples of the late gothic Manuelino style of Portuguese architecture (Fig. 1). The church and the monastery symbolize the Portuguese age of discovery and are among the most important and visited tourist attractions in Lisbon. In 1983, it was formally nominated by UNESCO as a world heritage site.

The monastery stretches over an area of approximately 300 by $50 \mathrm{~m}^{2}$ and develops around two courts [Fig. 2(a)]. The larger court is bordered by a two-story arcade, which hosts the National Archaeology Museum, the Maritime Museum, and the Central Library. The smaller court, the cloister, is bordered by the sacristy, the chapter room, the refectory, and the church of Santa Maria de
Belém, the object of this research. In geometrical terms, the church is $70 \mathrm{~m}$ long, $23 \mathrm{~m}$ wide ( $40 \mathrm{~m}$ in the transept), and $24 \mathrm{~m}$ high. As can be observed in Fig. 2(b), geometrically the church presents a cruciform layout with a single nave crossed by a transept with two lateral chapels and a chancel. The roof is composed of a single rib-vaulted ceiling with a 30-m span [Fig. 2(c)], supported by six columns with circular bases. A single bell tower, with a height of $50 \mathrm{~m}$, rises from the corner between the south and west façades.

The church is made of large blocks of a white fossiliferous limestone, called "calcário de lioz," which was quarried close by. The naves are covered with a slightly curved barred vault provided with stone ribs in a spider-web pattern. Two rows of octagonal columns, with a free height of $16 \mathrm{~m}$ and a radius ranging from $1.04 \mathrm{~m}$ (in the nave columns) to $1.88 \mathrm{~m}$ (in the nave-transept columns), almost imperceptibly divide the longitudinal naves, creating almost a single nave. The columns are connected to the vault by means of large fan capitals that reduce the free span of the nave.

The thickness of the walls varies from side to side, ranging from $1.90 \mathrm{~m}$ in the south wall to $2.65 \mathrm{~m}$ in the east walls (chancel side). Due to the presence of an internal staircase that provides access to the choir, the cloister, and the bell tower, the north wall has a thickness of about $3.5 \mathrm{~m}$. The south wall is cut by large openings and its stability is ensured by three trapezoidal buttresses, which are not aligned with the columns, indicating that the south wall was built prior to the construction of the vault. On the top of the vaults, brick masonry wallets, which were built during the 1930s, provide support for the roofing tiles.

\section{Description and Calibration of the Numerical Model}

The numerical model of the church was prepared using the finiteelement (FE) software DIANA version 10.1. As will be discussed in detail in the following sections, given the size and great complexity of the structure, it was necessary to adopt geometrical simplifications in the FE model in order to allow for an extensive nonlinear dynamic analysis within an acceptable processing time. However, special attention was given to the discretization of the model in order to reproduce the geometrical stiffness of the church as realistically as possible. The geometry of the $3 \mathrm{D}$ model and the mechanical properties of the materials, discussed in the following sections, were defined based on a set of nondestructive and laboratory tests (Roque 2010; Masciotta et al. 2016).

\section{Geometry}

The full numerical model is composed of 2,684 Timoshenko beam elements with quadratic interpolation and 4,242 nodes, corresponding to a total of 25,452 degrees of freedom (DoF) (Fig. 3). 


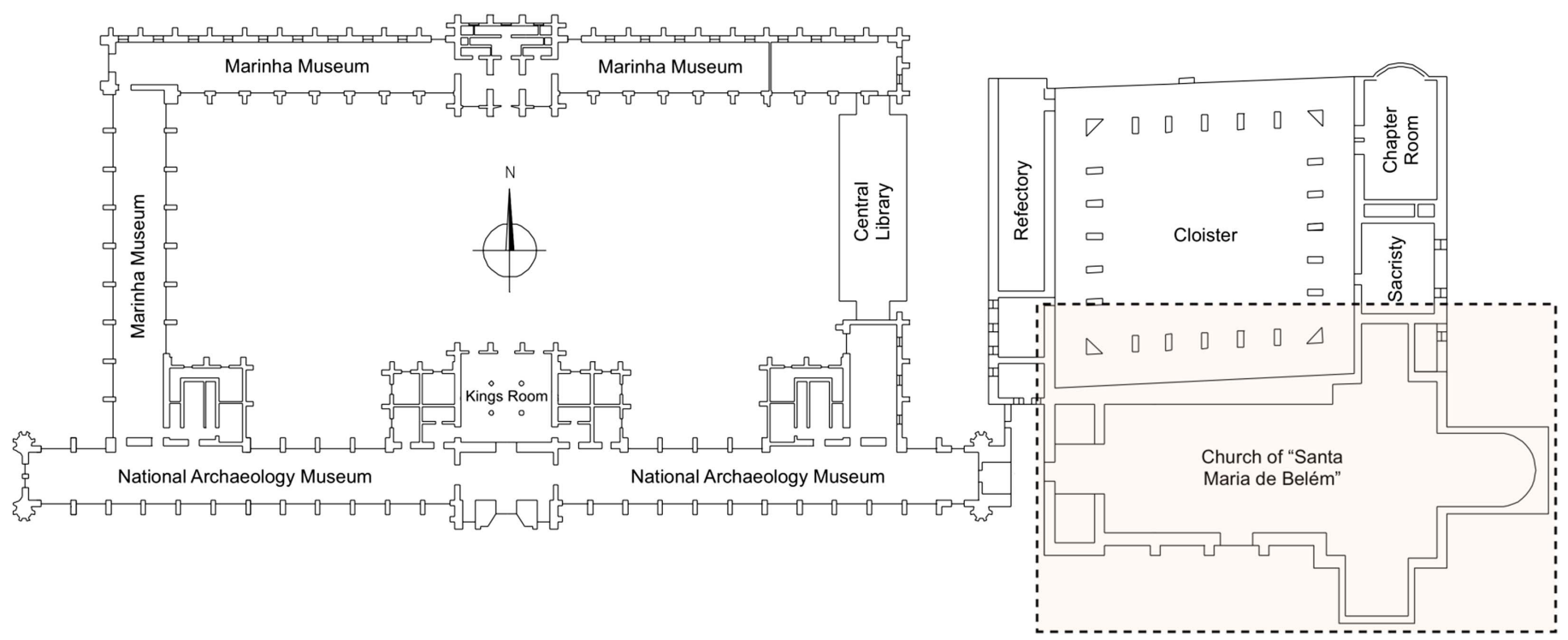

(a)

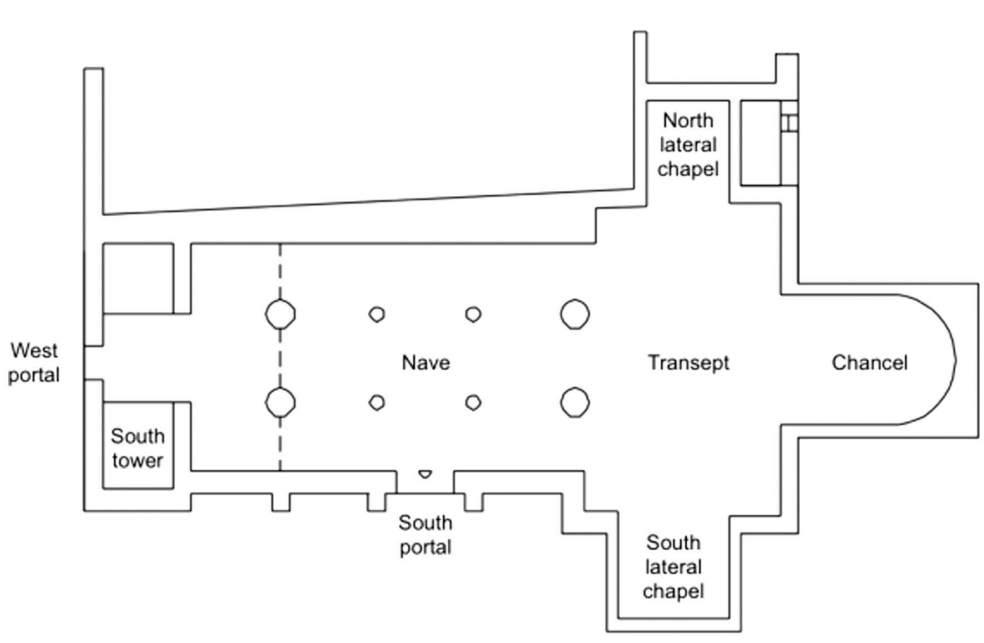

(b)

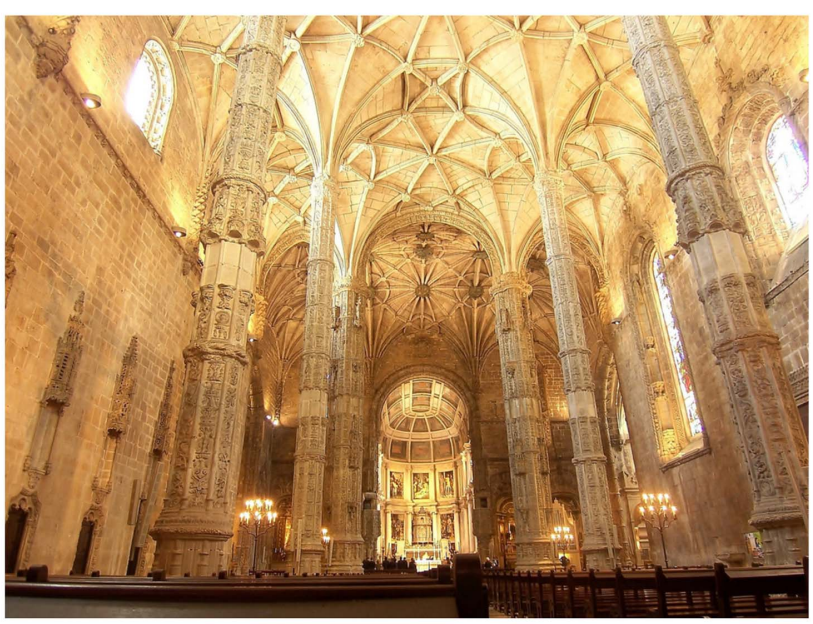

(c)

Fig. 2. Monastery of Jerónimos complex: (a) plan of the two courts; (b) plan of Santa Maria de Belém church; and (c) view of the ribbed vault (image by authors).

The supports were fully restrained, but rotations are allowed, according to the nonlinear material behavior adopted.

Special attention was paid to the modeling of the vault and the piers of the nave [Figs. 4(a and b)]. As detailed in Figs. 4(c and d), the rib profiles of the vault were modeled by beam elements with a trapezoidal cross section, whereas a T-shaped cross section was adopted for the rib-slab system. Given its marginal contribution to the structural response, the mortar layer covering the stone slabs was considered only in terms of equivalent mass.

Regarding the columns, depicted in Fig. 5, the octagonal geometry of the shaft was approximated by beam elements with a circular cross section. The capitals were represented at the base by elements with a cone-frustum geometry and, in the transition to the vault, by cuneiform elements radially set out. Given the poor mechanical properties of the infill material of the capitals, their contribution to the structural response of the church was neglected in the model. The walls were modeled by a grid of vertical and horizontal beam elements. Their mass was assigned to the vertical elements in order to avoid the occurrence of marginal flexural stresses due to gravity load in the horizontal elements.

\section{Material Properties and Model Parameters}

A wide range of sophisticated mechanical models have been developed to predict the nonlinear behavior of masonry material both in tension (low tensile capacity with consequent cracking phenomena) and compression, including individual failure and damage mechanisms (Ferreira et al. 2015a). Unfortunately, some of these models are rather difficult to apply to the 3D analysis of complex structural systems, not only because of the large number of parameters involved in the definition and updating of the mechanical model but also because of the number of DoF required to mesh the structure (Betti et al. 2011).

Following a critical review of the nonlinear material models available in the literature (Lourenço 2002), the physical nonlinear behavior of the masonry material was simulated in this work using a distributed plasticity formulation based on the total strain crack model, detailed in the DIANA software. A parabolic stress-strain relation was used, in which the compressive strength $f_{c}$ was assumed equal to $10 \mathrm{MPa}$ [estimated from a reference value obtained experimentally by taking into account the dispersion of the results [coefficient of variation (CV) of approximately 30\%, and a safety 


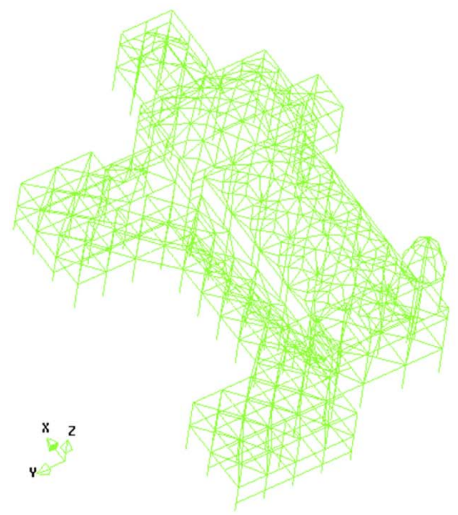

(a)

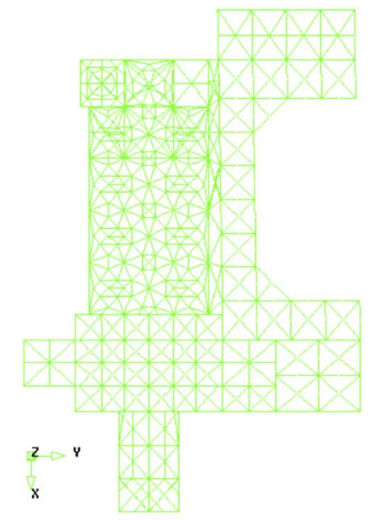

(b)

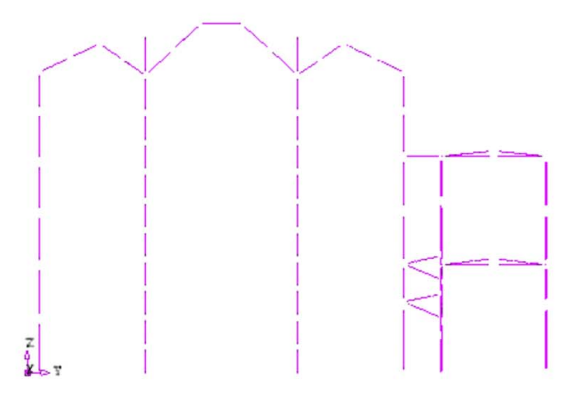

(c)

Fig. 3. Finite-element model: (a) 3D view; (b) plan view; and (c) central arcade of the nave in transverse direction. (Reprinted from Construction and Building Materials, Vol. 116, M.-G. Masciotta, J. C. A. Roque, L. F. Ramos, and P. B. Lourenço, "A multidisciplinary approach to assess the health state of heritage structures: The case study of the Church of Monastery of Jerónimos in Lisbon," pp. 169-187, (C) 2016, with permission from Elsevier.)

factor for ancient masonry equal to 3.0]; further details on this can be found in Roque (2010) and Masciotta et al. (2016)] and the tensile strength $f_{t}$ was assumed equal to $0.01 \mathrm{MPa}$. The fracture energy in compression $G_{C}$ was $16 \mathrm{~kJ} / \mathrm{m}^{2}$. The postcracking shear behavior was modeled assuming a constant value for the shear retention faction $\beta$ equal to 0.01 (Scotta et al. 2001), which implies no postpeak shear capacity. Finally, the material was assumed to be homogeneous, with an elastic modulus $E$, calibrated with in situ tests and 0.2 for the Poisson's ratio $v$. The weight per volume unit $\gamma$ adopted for the masonry material was $24 \mathrm{kN} / \mathrm{m}^{3}$.

\section{Calibration Procedure}

Once built, the numerical model was calibrated, both in the linear and nonlinear domains, from a set of experimental and numerical results. In the first phase (linear domain), the results of the static linear analyses were compared with corresponding results obtained from a partial numerical model of the nave, in which 3D elements were used to study the behavior of the vault under vertical actions (Lourenço et al. 2007). Following this procedure, it was possible to calibrate the geometric stiffness of some the church substructures, namely the vault curvatures. In a second phase, based on the experimental results obtained from the dynamic identification of the columns and the nave vault [further details on this work can be found in Roque (2010) and Masciotta et al. (2016)] and from the mechanical characterization of the masonry, the elastic modulus of the columns and the equivalent stiffness of the remaining substructures of the church were assumed to be equal to 30 and
$12 \mathrm{GPa}$, respectively. The first 16 numerical mode shapes found for the church were essentially related to resonant frequencies of the main nave and its columns. Table 1 presents the best correlations found between the experimental and calibrated numerical eigenfrequencies for the nave and the columns, including the corresponding error.

The intent was to perform nonlinear dynamic analyses; because the adjacent buildings provide restraint effects on the church, portions of them were included in the geometrical model, using a coarse mesh to limit the computational effort. Sensitive modal analyses were performed until the results were independent of the included volume. The parabolic stress-strain relation adopted to perform nonlinear dynamic analyses was adjusted based on a previous sensitive pushover analysis, because the results showed an unfeasible available ductility in compression for masonry material when a preliminary perfect elastic-plastic material relation was used.

After the aforementioned calibration procedures, the results from the long-term static monitoring system-which revealed the presence of cyclic oscillations on the top of the nave columns due to seasonal fluctuations in temperature [with a rate of about $0.01 \mathrm{~mm} / \mathrm{m} /{ }^{\circ} \mathrm{C}$; see Roque (2010) and Masciotta et al. (2016)]were used to check the ability of the model to reproduce the oscillations. In addition, the accelerations due to a small seismic event (which occurred on February 12, 2007) registered by the dynamic monitoring system were used as excitation to try to numerically reproduce the observed behavior. As post action, very low modal frequency changes were detected on the main nave. Considering the complexity of the structure and the model, a satisfactory numerical agreement was reproduced in both situations. Nonetheless, it would be desirable in future work to validate the global model resorting to more detailed analyzes focused on particular structural elements (e.g., the columns of the nave).

\section{Nonlinear Dynamic Analysis}

As mentioned previously, the seismic response of the church of Santa Maria de Belém was evaluated using linear static, nonlinear static, and nonlinear dynamic approaches. Although this paper is focused on the nonlinear dynamic analysis of the structure, the results obtained from the linear and nonlinear static analyses, presented in Masciotta et al. (2016), are fundamental to a better understanding of the nonlinear dynamic response of the structure. Therefore, the most important remarks obtained from those analyses are briefly summarized here. The bearing capacity of the church under gravity loading is considerably affected by the structural behavior of the nave columns. The collapse mechanism of the church under gravity loads is associated with the failure of the north column of the central arcade, which presents a sudden loss of bearing capacity related to an increase in the horizontal and vertical displacements. Despite the high slenderness of the columns, the structural performance of the church for vertical loading is good.

The nonlinear dynamic analysis performed in this work aimed at investigating the seismic behavior of the church, paying particular attention to previously identified vulnerabilities. For such, a series of acceleration time histories were selected, taking into consideration the two principal seismological areas likely to affect the city of Lisbon: the first is located in the adjacent Atlantic zone, in the southeast of the São Vicente cape (far-field scenario); the second is located in the north of Lisbon, at Lower Tagus Valley (near-field scenario).

Due to a lack of consistent real seismic records in mainland Portugal, the authors resorted to artificial records generated by 


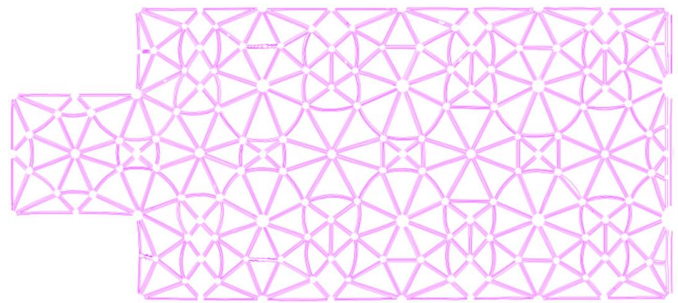

(a)

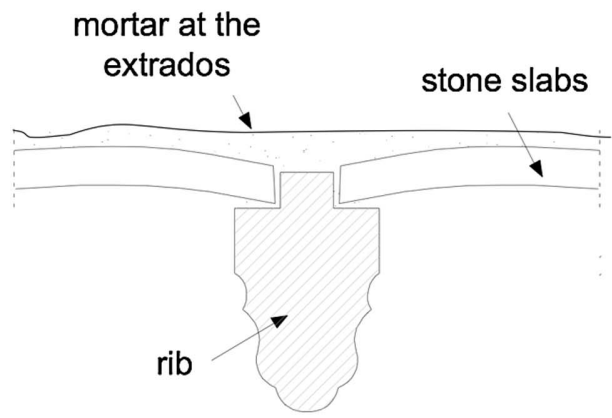

(c)

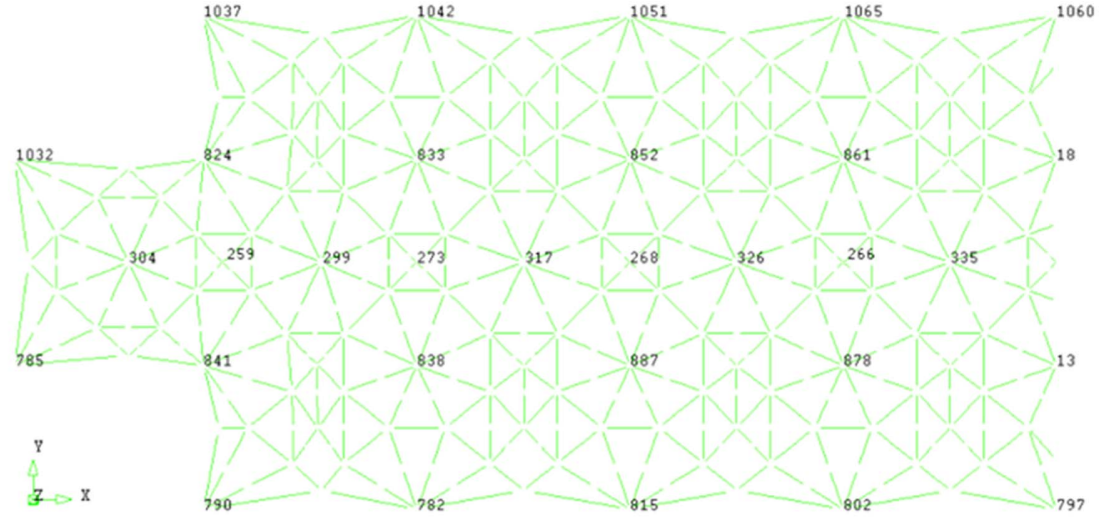

(b)

Fig. 4. Finite-element model: (a) actual; (b) approximated configuration of the nave vaults; (c) existing; and (d) geometric model adopted for the rib profiles of the vaults.

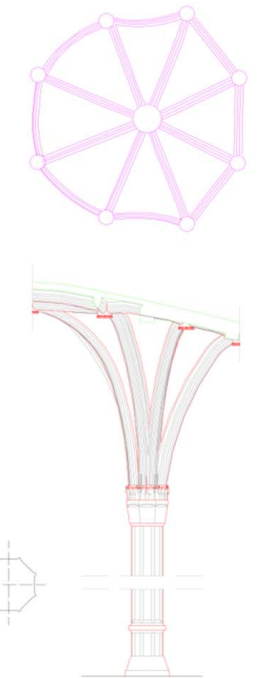

(a)

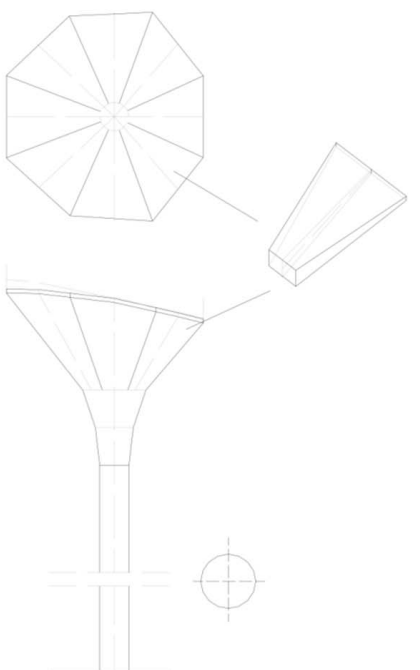

(b)

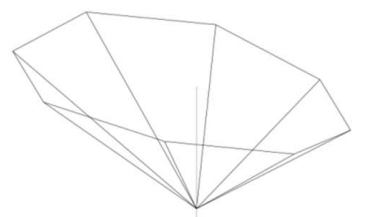

(c)

Fig. 5. Finite-element model: (a) existing; (b) approximated configuration; and (c) geometric model adopted for the columns. (Reprinted from Construction and Building Materials, Vol. 116, M.-G. Masciotta, J. C. A. Roque, L. F. Ramos, and P. B. Lourenço, "A multidisciplinary approach to assess the health state of heritage structures: The case study of the Church of Monastery of Jerónimos in Lisbon,” pp. 169-187, (C) 2016, with permission from Elsevier.)

the Earthquake Engineering and Structural Dynamics Division department (NESDE) at the National Laboratory of Civil Engineering (LNEC) in Lisbon, the main features of which can be found in Carvalho et al. (2004). Based on scenarios presented by Sousa
(2006), acceleration time series were synthesized for each return period, considering only the Atlantic seismic source, which corresponds to a far-field earthquake. In addition, given the importance of the building, scenarios with return periods of 5,000 years were 
Table 1. Correlation between numerical and experimental frequencies found for nave and columns

\begin{tabular}{|c|c|c|c|c|}
\hline \multicolumn{2}{|c|}{ Numerical mode shapes } & \multicolumn{2}{|c|}{ Experimental mode shapes } & \multirow[b]{2}{*}{ Error $(\%)$} \\
\hline Mode (\#) & Frequency $(\mathrm{Hz})$ & Mode (\#) & Frequency $(\mathrm{Hz})$ & \\
\hline \multicolumn{5}{|c|}{ Nave (global modes) } \\
\hline $1 \mathrm{st}$ & 3.79 & 1 st & 3.69 & 2.6 \\
\hline 4th & 5.34 & 2nd & 5.12 & 4.1 \\
\hline 7th & 6.23 & $3 \mathrm{rd}$ & 6.29 & 1.0 \\
\hline 10th & 6.61 & 4th & 7.23 & 9.4 \\
\hline \multicolumn{5}{|c|}{ Columns of the nave (local modes) } \\
\hline 15th & 7.39 & $1 \mathrm{st}$ & 7.36 & 0,4 \\
\hline 16th & 7.51 & 2 nd & 7.52 & 0,1 \\
\hline
\end{tabular}

Table 2. Seismic scenarios adopted and main parameters of the corresponding artificial records

\begin{tabular}{lccccc}
\hline $\begin{array}{l}\text { Return } \\
\text { period }\end{array}$ & Magnitude & $\begin{array}{c}\text { PGA } \\
(\mathrm{g})\end{array}$ & $\begin{array}{c}\text { Frequency } \\
\text { domain }(\mathrm{Hz})\end{array}$ & $\begin{array}{c}\text { Duration } \\
(\mathrm{s})\end{array}$ & Input ID \\
\hline 475 years & $M_{w}=7.4$ & 0.10 & 5.60 & 10.20 & 475_M74_1 \\
& & 0.09 & 5.60 & 10.60 & 475_M74_2 \\
& & 0.12 & 3.00 & 7.70 & 475_M74_3 \\
975 years & \multirow{2}{*}{$M_{w}=7.8$} & 0.17 & 4.50 & 14.90 & 975_M78_1 \\
& & 0.16 & 7.10 & 13.90 & 975_M78_2 \\
& & 0.14 & 5.60 & 15.00 & 975_M78_3 \\
5,000 years & \multirow{2}{*}{$M_{w}=8.2$} & 0.21 & 3.00 & 20.29 & 5000_M82_1 \\
& & 0.23 & 5.60 & 20.71 & 5000_M82_2 \\
& & 0.21 & 3.60 & 20.75 & 5000_M82_3 \\
\hline
\end{tabular}

also considered. Ten accelerograms were generated for each return period. Of the ten accelerograms, due to the long time required to carry out nonlinear dynamic analyses, only the three characterized in Table 2 were actually used. For all generated accelerograms, the focal distance was equal to $205 \mathrm{~km}$, and the frequency content was similar. The selection of the three signals was based on their sustained maximum acceleration (SMA). For easy interpretation, each analysis is named with an acronym (the input ID in Table 2); the prefix indicates the return period $(475,975$, or 5,000$)$, the central text refers to the magnitude of the earthquake $(7.4,7.8$, or 8.2$)$, and the final portion is the analysis number (1-3). Peak ground acceleration is abbreviated as PGA in the table.

All numerical simulations were performed with the DIANA software, considering material and geometric nonlinear behavior and using the regular Newton-Raphson method combined with an energy convergence criterion established as less than or equal to $10^{-3}$. The Hilber-Hughes-Taylor (HHT) method was used to integrate the system of differential equations of motion with a parameter $\alpha=-1 / 3$ to control the numerical damping (Hilber et al. 1977). Following the established formulation for time step integration $\left(\Delta t<0.1 T_{\min }\right)$ and considering $7.5 \mathrm{~Hz}$ as the highest significant frequency of interest (the dominant numerical frequencies of the nave and the columns within the first 16 modes are under $7.51 \mathrm{~Hz}$; see Table 1 ), a time step of $\Delta t=0.01 \mathrm{~s}$ was adopted.

Viscous Rayleigh damping formulation was used in order to take into account the energy dissipation mechanisms not associated with the hysteretic behavior of the structure. A low damping coefficient ( $\xi=1.5 \%)$ was adopted in order to avoid Rayleigh overdamping and to promote the hysteretic damping (Roque 2010). Since the central arcade, transverse to the nave, had been identified as the potentially most vulnerable substructure of the church [Fig. 3(c)], the following discussion will focus primarily on this portion of the church. The behavior of the south tower belfry is also addressed.

\section{Seismic Structural Performance Assessment: Results and Data Interpretation}

With the fundamental aim of identifying the occurrence of potential structural collapses for the different return periods considered (475, 975 , and 5,000 years), the time history response of the structure was investigated in terms of the following parameters: vertical reaction of the columns; vertical displacement of the vault key; horizontal displacement of the columns; horizontal top displacement of the north and south walls; horizontal displacement of the top node of the tower belfry; and the normal tensile stress of belfry's vertical elements. From the analysis of the results obtained for the seismic scenarios with return periods of 475 and 975 years, no indication of potential collapse of the church was found. However, for a return period of 5,000 years it was possible to observe changes in the structural response of the church that are related to the development of partial collapse mechanisms.

In the direction transverse to the nave, the seismic response of the central arcade denotes a clear frame action (column-wall) resulting in high axial load variations in the columns ranging from $-90 \%$ to $+91 \%$ with respect to gravity load (return period of 5,000 years) (Figs. 6-8). The changes in structural performance can be clearly observed from the horizontal reaction time-history response of the columns (Fig. 9); the collapse begins with a sudden reduction on the north column (about 12-13 s) and is accompanied by an increase on the south column.

These changes are also evident in the horizontal deformability of the central arcade, mainly concentrated at the column shafts. However, the low amplitude of the transverse displacements

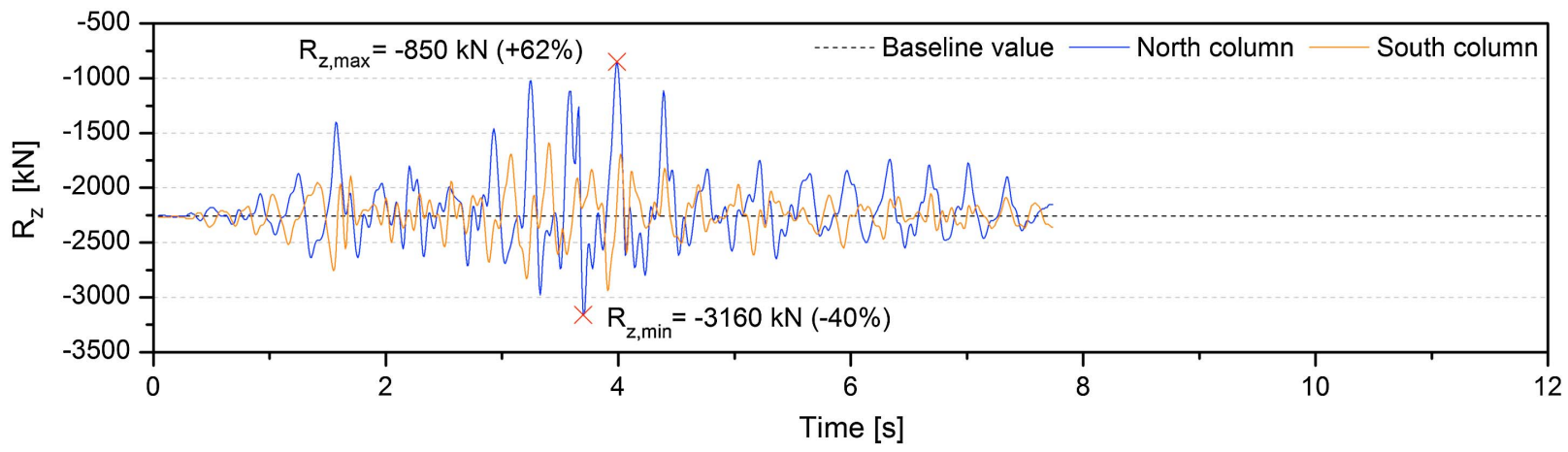

Fig. 6. Time history of vertical reactions at the north and south columns for a return period of 475 years (seismic input $475 \_$M74_3). 


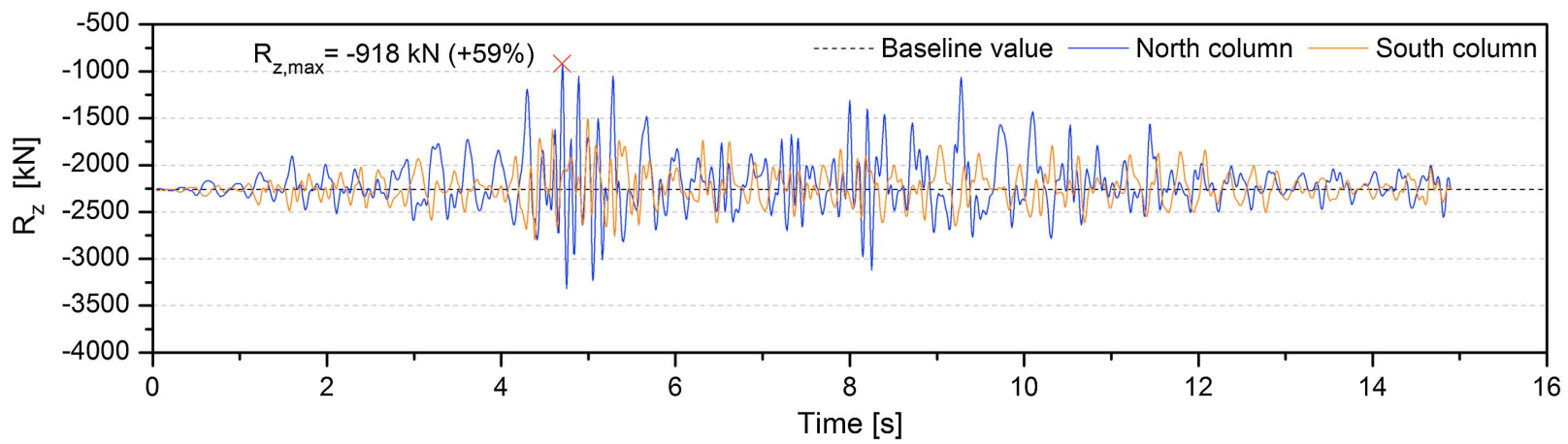

Fig. 7. Time history of vertical reactions at the north and south columns for a return period of 975 years (seismic input 975_M78_1).

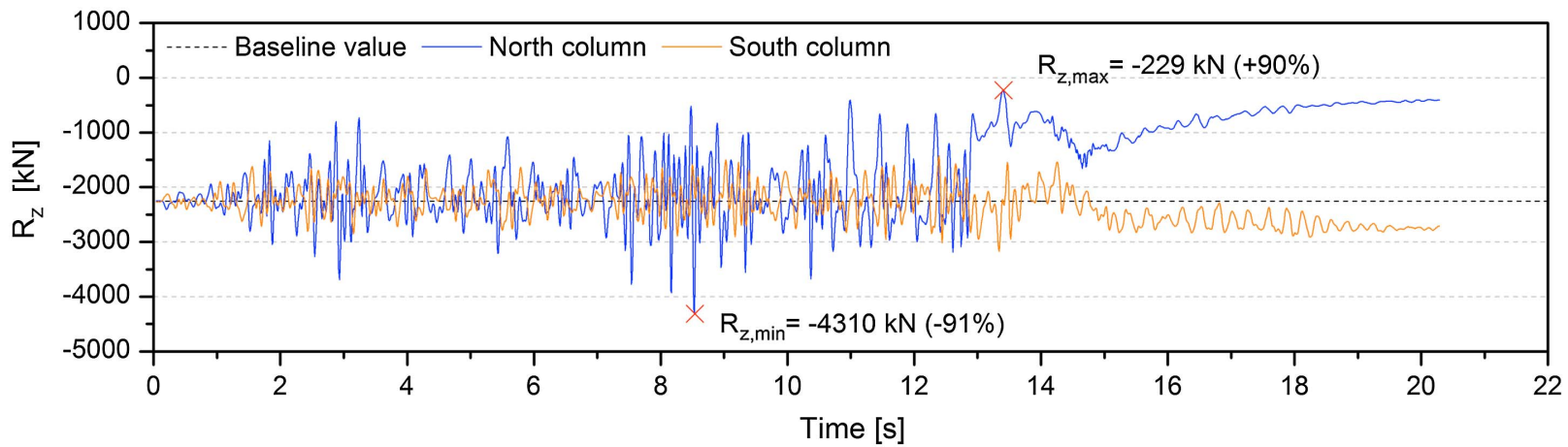

Fig. 8. Time history of vertical reactions at the north and south columns for a return period of 5,000 years (seismic input 5000_M82_2).

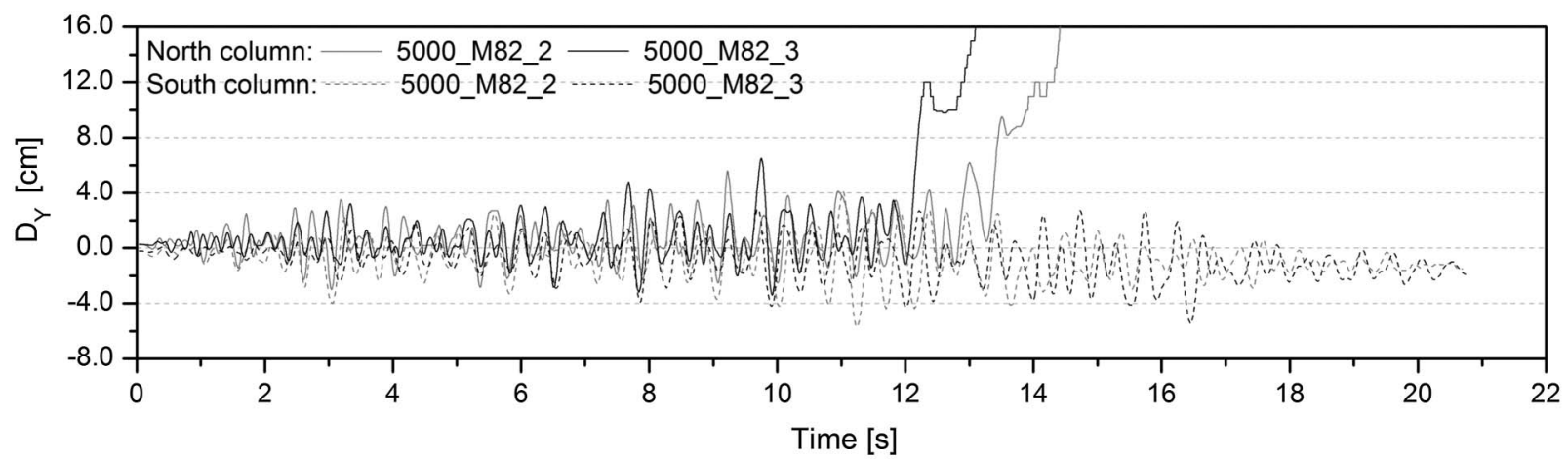

Fig. 9. Time history of horizontal displacements at the shafts of the north and south columns.

indicates an unimportant contribution of the nonlinear geometric effects to the structural performance of the vertical elements. Even for the 5,000-year scenario, during the precollapse phase of the columns, the small amplitude of the displacements seems to present a small contribution to the onset of collapse. Indeed, the maximum transverse displacements obtained in the north column for the 5,000-year scenario (during the precollapse period) were $6.2 \mathrm{~cm}$ $(0.52 \%$ drift $)$ on the shaft and $3.9 \mathrm{~cm}(0.21 \%$ drift $)$ on the top. However, on top of the lateral walls, the maximum transverse displacements obtained during the precollapse period were $4.1 \mathrm{~cm}(0.20 \%$ drift) and $2.6 \mathrm{~cm}(0.42 \%$ drift $)$ in the south and north walls, respectively (at the level of the cloister roof).

Although the south tower belfry appears to be one of the most vulnerable elements of the church, and despite the severity of the seismic scenario with a 5,000-year return period, the horizontal top displacements of the south tower belfry were rather small, with amplitudes less than $2.5 \mathrm{~cm}$. However, the analysis of the axial tensile stress time history for all four vertical belfry elements (not presented here for the sake of brevity) showed some occurrences with simultaneous tension in two of those elements, indicating the development of a possible overturning collapse mechanism.

Finally, the potential collapse mode pattern found for the 5,000year return period scenario is illustrated in Fig. 10, in which the collapse of the north columns and the consequent partial collapse of the nave vault can be clearly observed. These results not only confirm the higher vulnerability of the nave in the transverse direction (as observed in the previous static analyses) but also confirm 


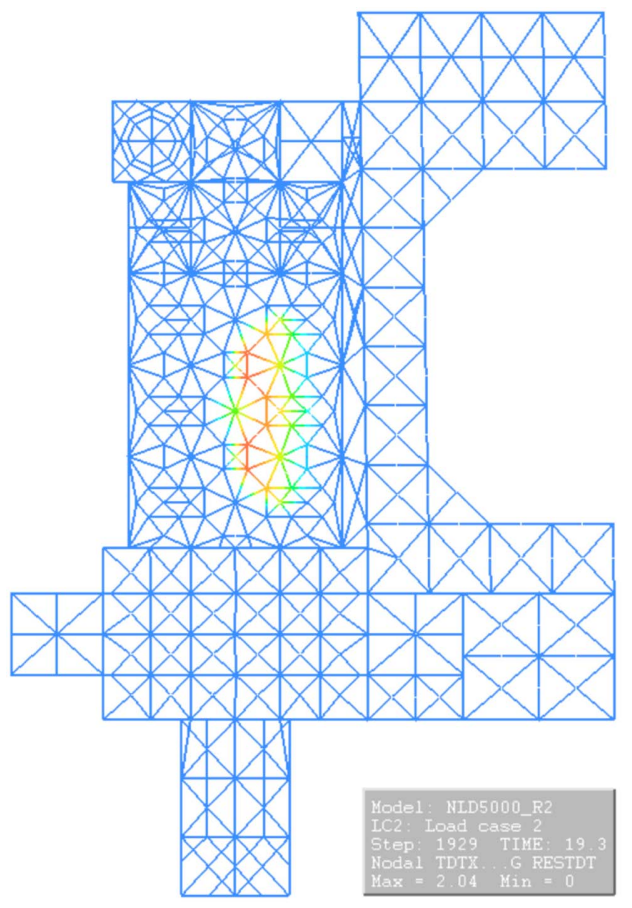

(a)

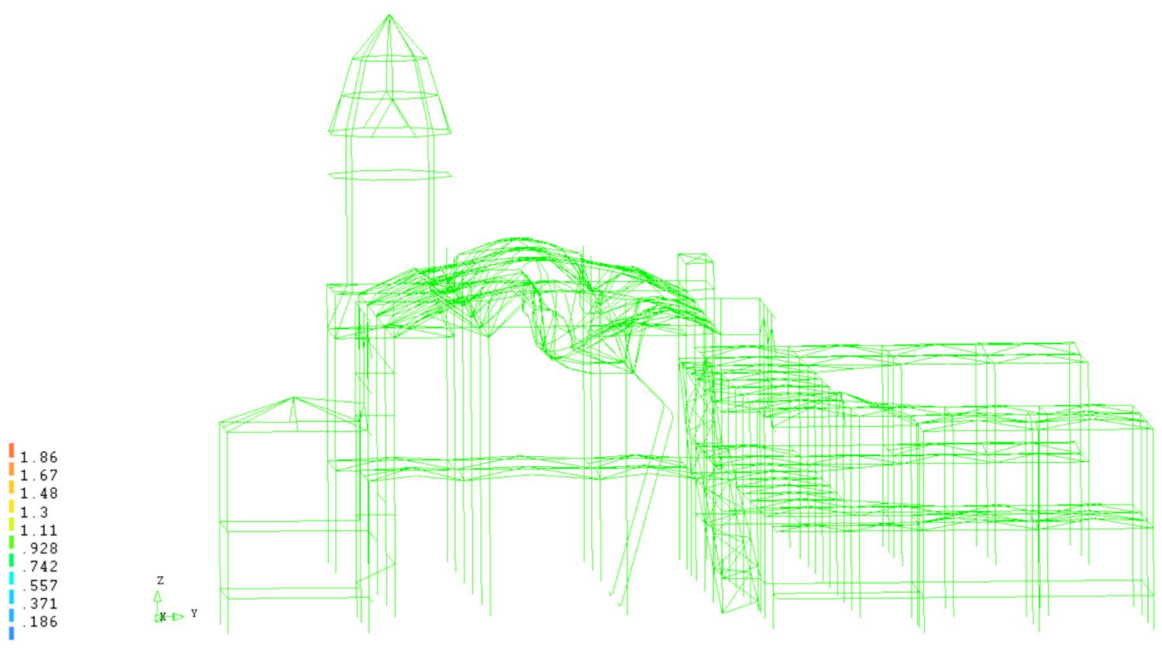

(b)

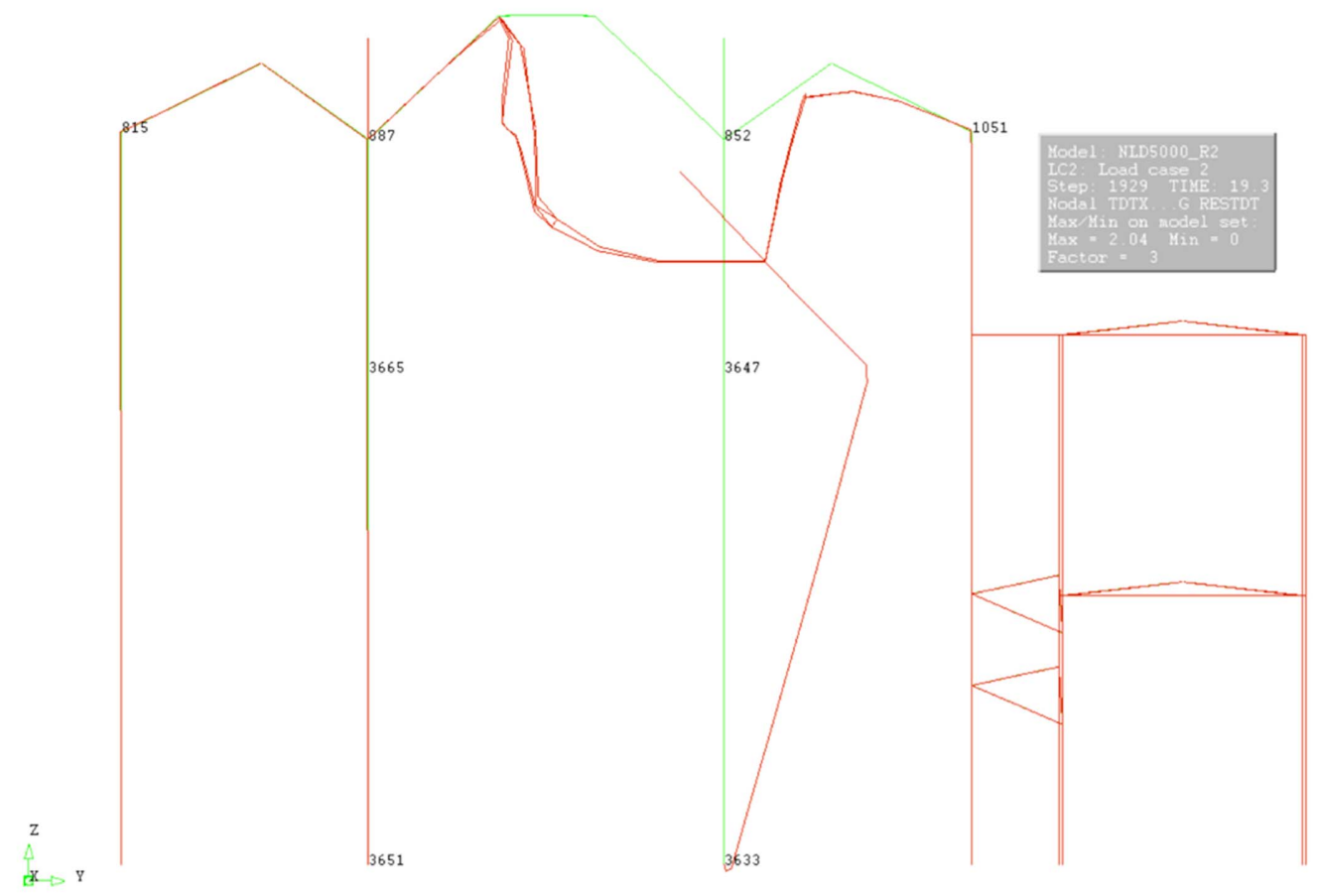

(c)

Fig. 10. Configuration of the potential collapse mode from the analysis of 5000_M82_2: (a) plan view; (b) perspective; and (c) central arcade transverse to the nave.

the vulnerability of the nave columns and their key role in the seismic behavior of the church.

\section{Earthquake-Induced Damage Analysis}

Because the dynamic response of the church to the seismic excitation with a 5,000-year return period reveals the occurrence of potential collapse mechanisms involving the central arcade of the nave, the subsequent discussion focus on investigating damage to its structural elements (namely, the columns and the walls). The response of the north column is presented in the form of a bending moment-curvature diagram and stress-strain curve (for the most compressed fibers) at the bottom, middle, and top sections. The moment-curvature diagrams presented in Fig. 11(a) confirm the asymmetric behavior of the 

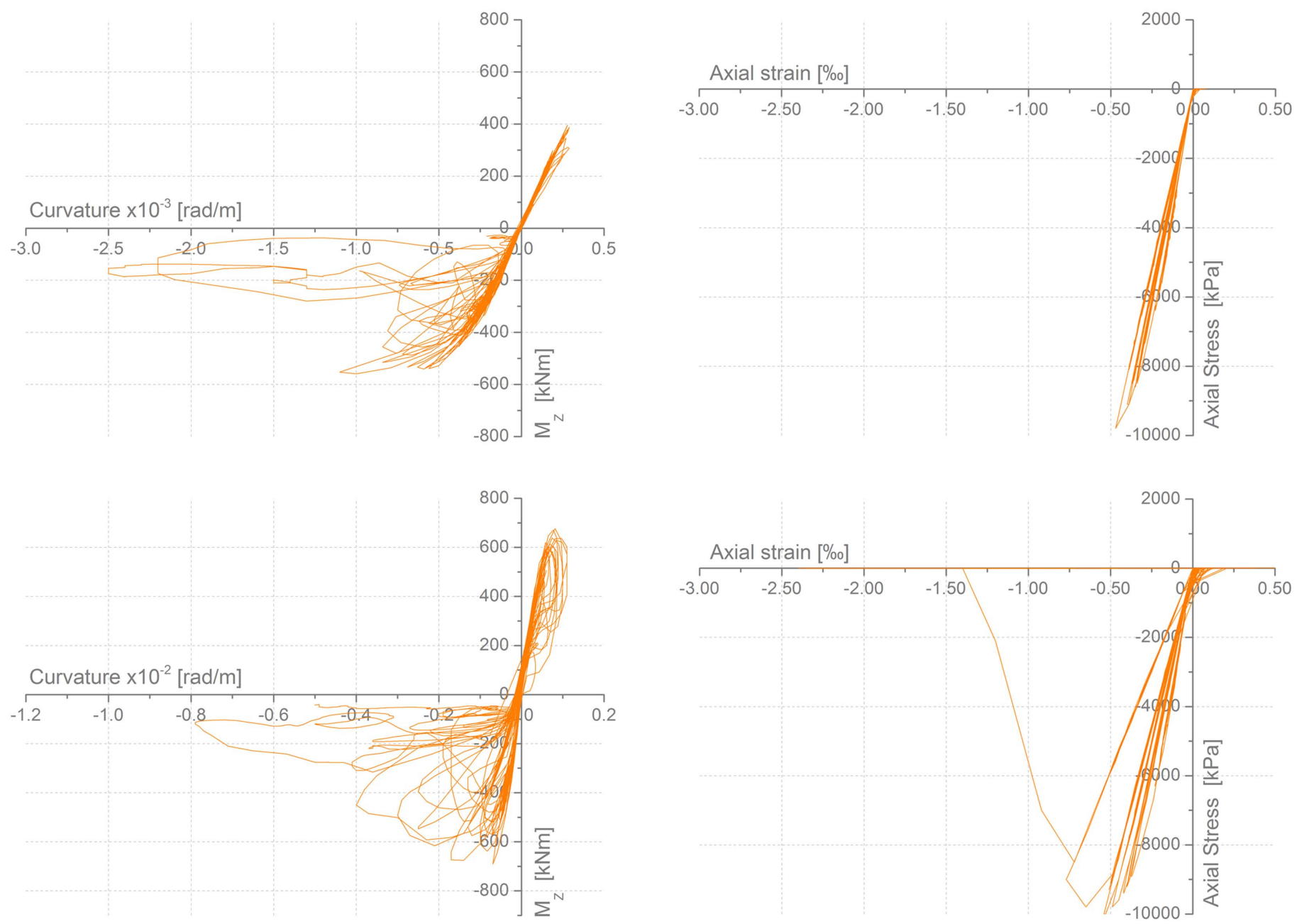

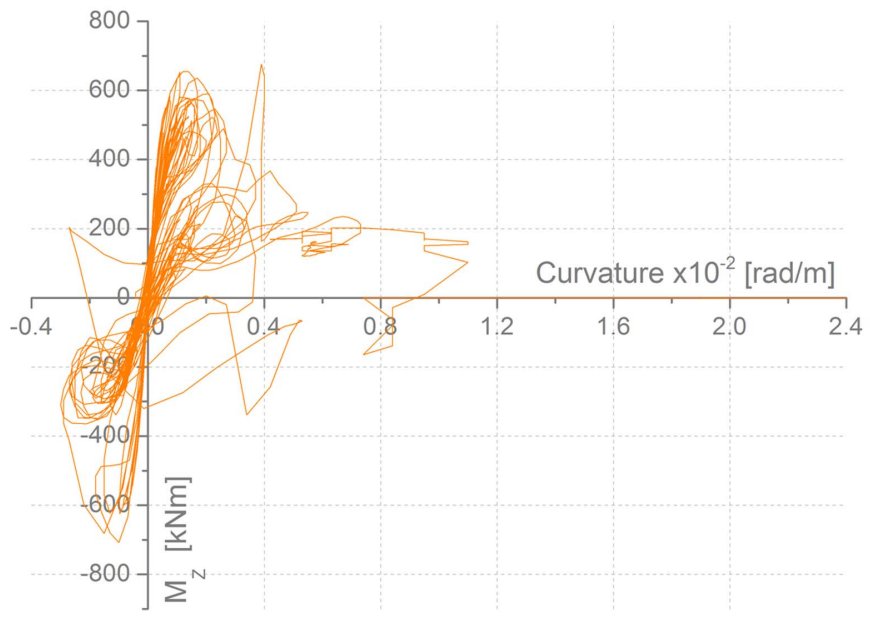

(a)

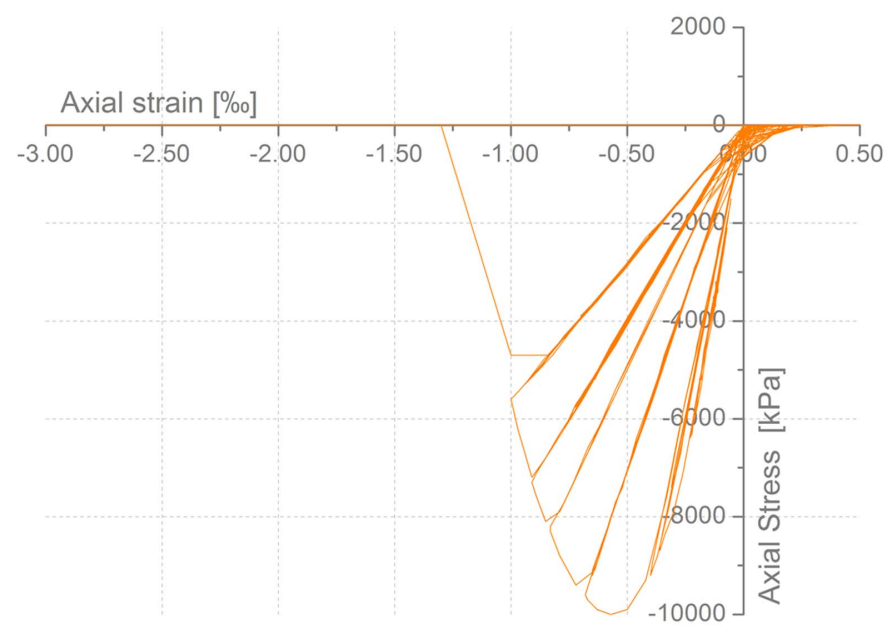

(b)

Fig. 11. Response of the north column obtained from seismic input 5000_M82_2: (a) moment-curvature diagrams; and (b) stress-strain curves of the most compressed fibers.

column sections due to the seismic increase in eccentric compression resulting from dead loads. Stiffness and flexural strength degradation of the sections is evident from the hysteretic behavior associated with progressive damage, which culminates in total loss of strength at the bottom section. The stress-strain curves presented in Fig. 11(b) also evidence high damage under compression at the bottom and middle sections and a significant level of cracking $\left(\varepsilon_{\text {axial }} \gg \varepsilon_{c k}\right)$ present in all sections. Because the axial strains are less than $0.5 \%$ at the top section, no damage in compression is found.

Applying the same reasoning to the south column, bending moment-curvature diagrams and stress-strain curves are given in Fig. 12 for the same critical sections. 

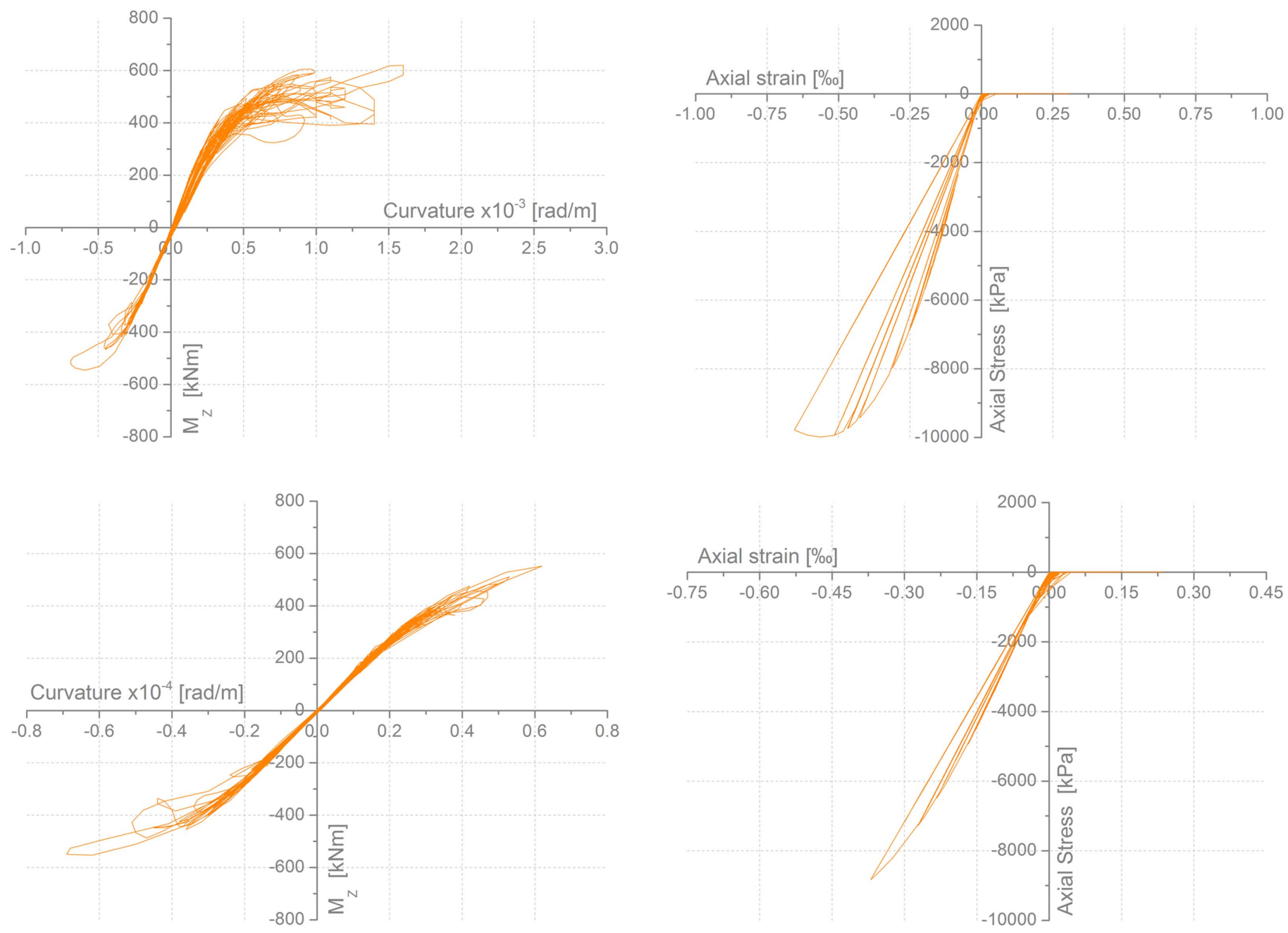

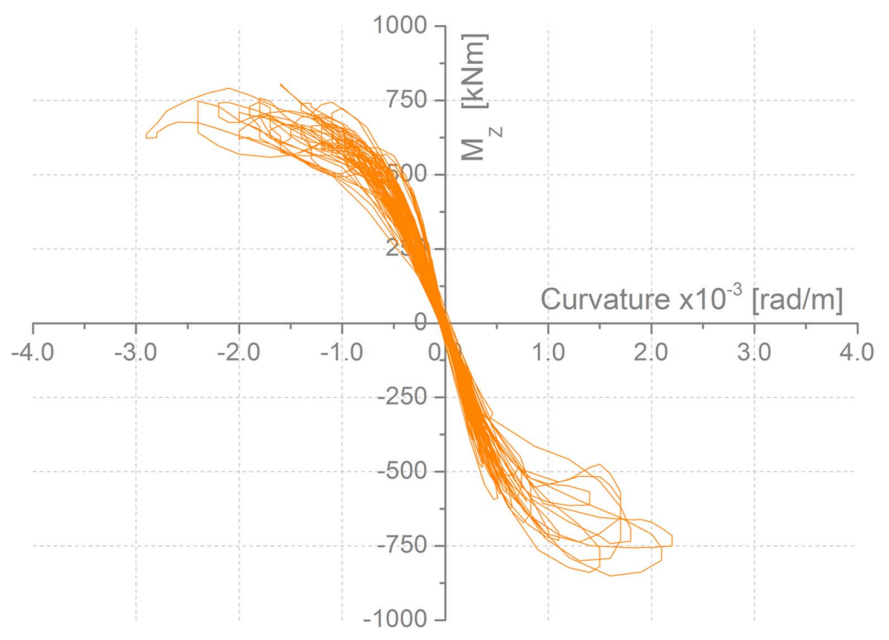

(a)

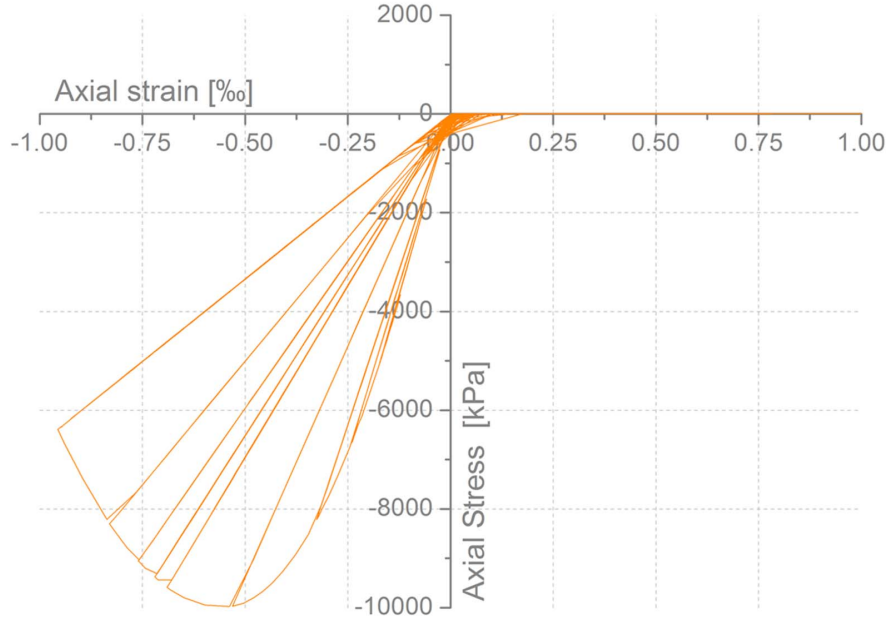

(b)

Fig. 12. Response of the south column obtained from seismic input 5000_M82_2: (a) moment-curvature diagrams; and (b) stress-strain curves of the most compressed fibers.

The nonsignificant hysteresis observed in the moment-curvature diagram given in Fig. 12(a), reveals that the sections of the south column have not completely lost their flexural strength capacity. However, in the bottom section, the failure of the most compressed fibers is prominent (postpeak instability) [Fig. 12(b)].
The asymmetric behavior of the nave columns due to the asymmetry of the central arcade is also apparent in the load interaction $\mathrm{N}-\mathrm{M}$ diagram [axial load $(\mathrm{N})$ versus bending moment $(\mathrm{M})$ ], presented in Fig. 13, which reveals that the collapse of the central north column is conditioned by the combination of moderated axial 


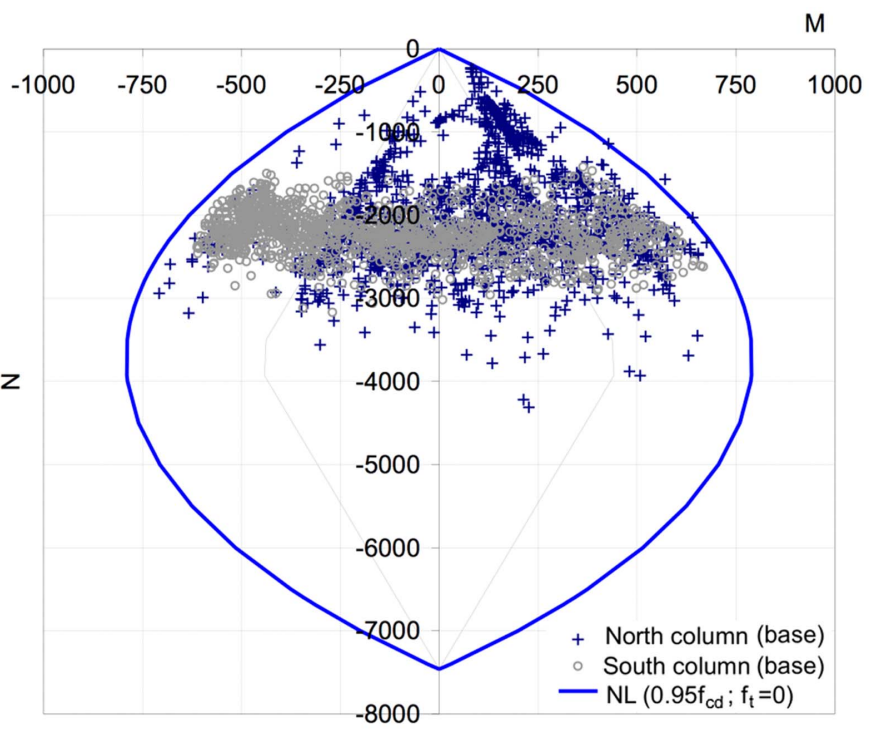

(a)

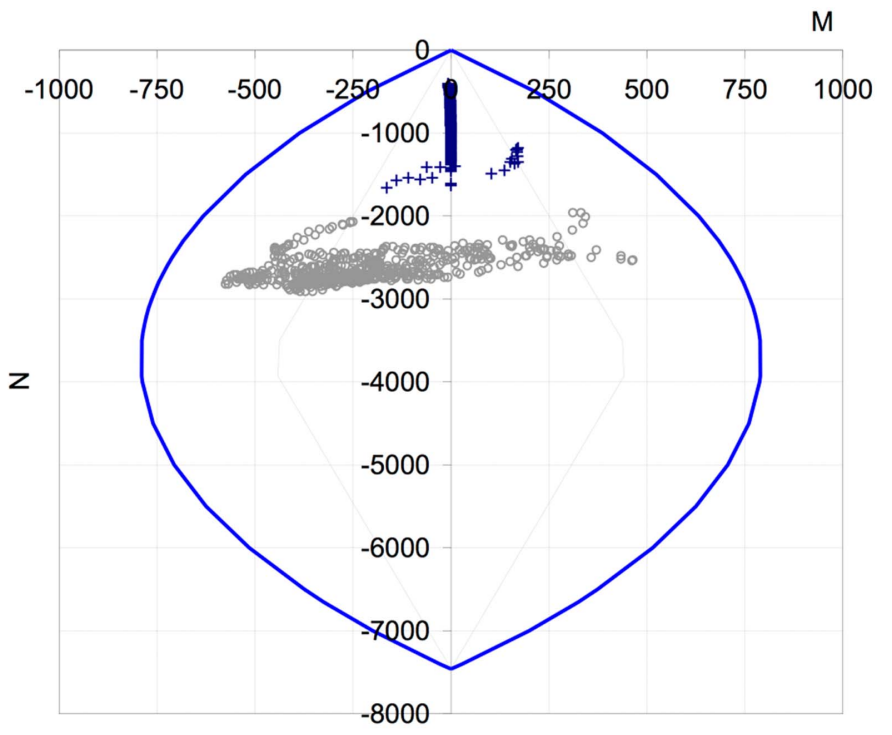

(b)

Fig. 13. N-M interaction diagram at the base of the north and south columns: (a) before; and (b) after the beginning of collapse (seismic input 5000_M82_2).

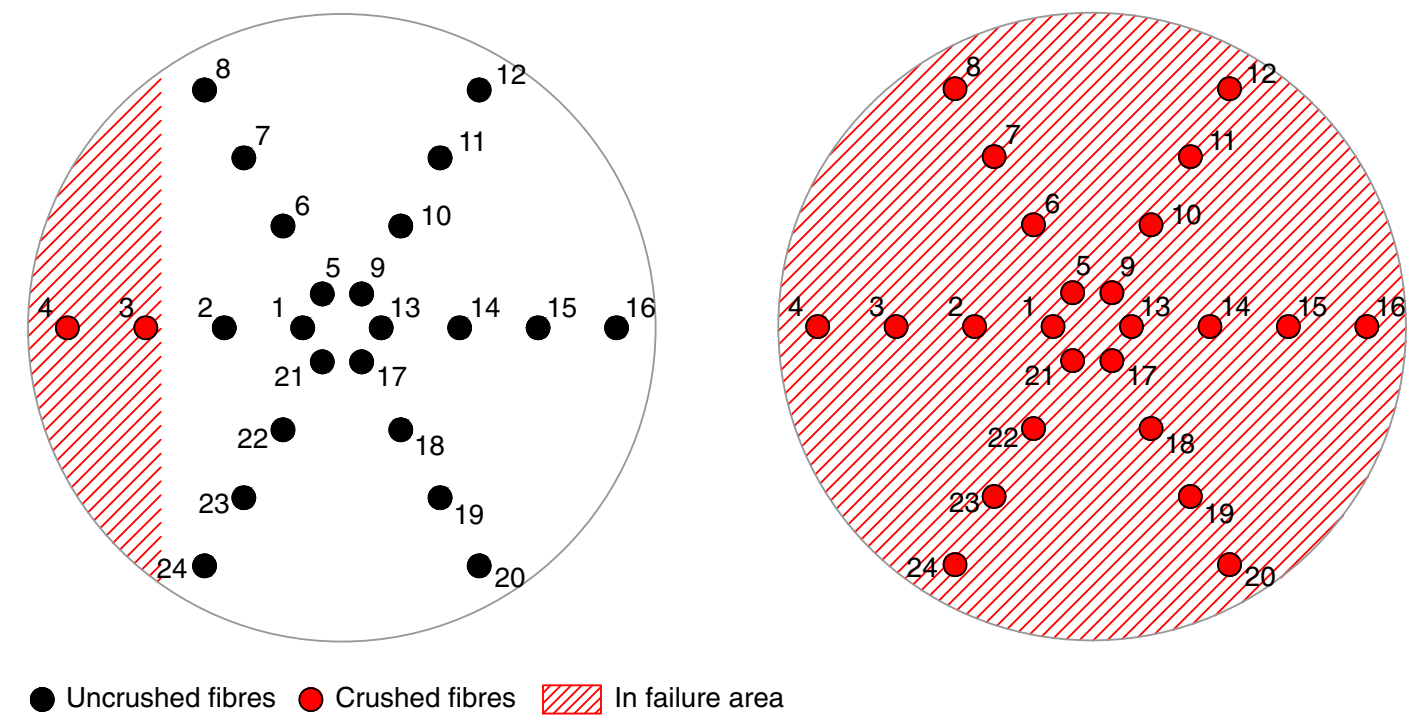

Fig. 14. Schematic representation of the compressive damage in the middle section of the shaft and in bottom section of the north column (seismic input 5000_M82_2).

compression loads $(v<0.40)$ with large bending moment values, resulting in high levels of eccentric compression in the section.

Complementarily, a schematic representation of the damage found in the base and middle sections of the north column is depicted in Fig. 14. As can be observed, the collapse of the north column is characterized by a total failure in the base section (crushing of the effective section) and a partial failure in the shaft section (crushing of the most compressed fibers).

Regarding the lateral walls of the nave, seismic damage was analyzed in the critical section of the central buttresses by means of the moment-curvature diagram and stress-strain curve presented in Fig. 15. High levels of cracking were found on both walls, but low compressive damage (which was particularly noticeable on the north wall) were also found.

Finally, with compressive stress values lower than 1.0 MPa, which are quite low compared with the maximum capacity (which was assumed as $10 \mathrm{MPa}$ ), no compressive damage is expected in the south tower belfry. However, normal tensile stresses and cracking were noted in the all vertical elements of the belfry. Similar results were obtained with the 5000_M82_2 input; for this reason, those results will not be discussed here.

As a final note, it should be stressed that for the scenarios with return periods of 475 and 975 years, a generalized level of cracking and important states of stress were found in the nave substructures (columns, walls, and vault) after seismic excitation.

\section{Discussion of the Base Shear Results}

The base shear results in the transverse nave direction obtained from the dynamic analyses, considering different return periods, are presented and discussed in this section. The discussion considers two levels: the structural response of the church globally, and 


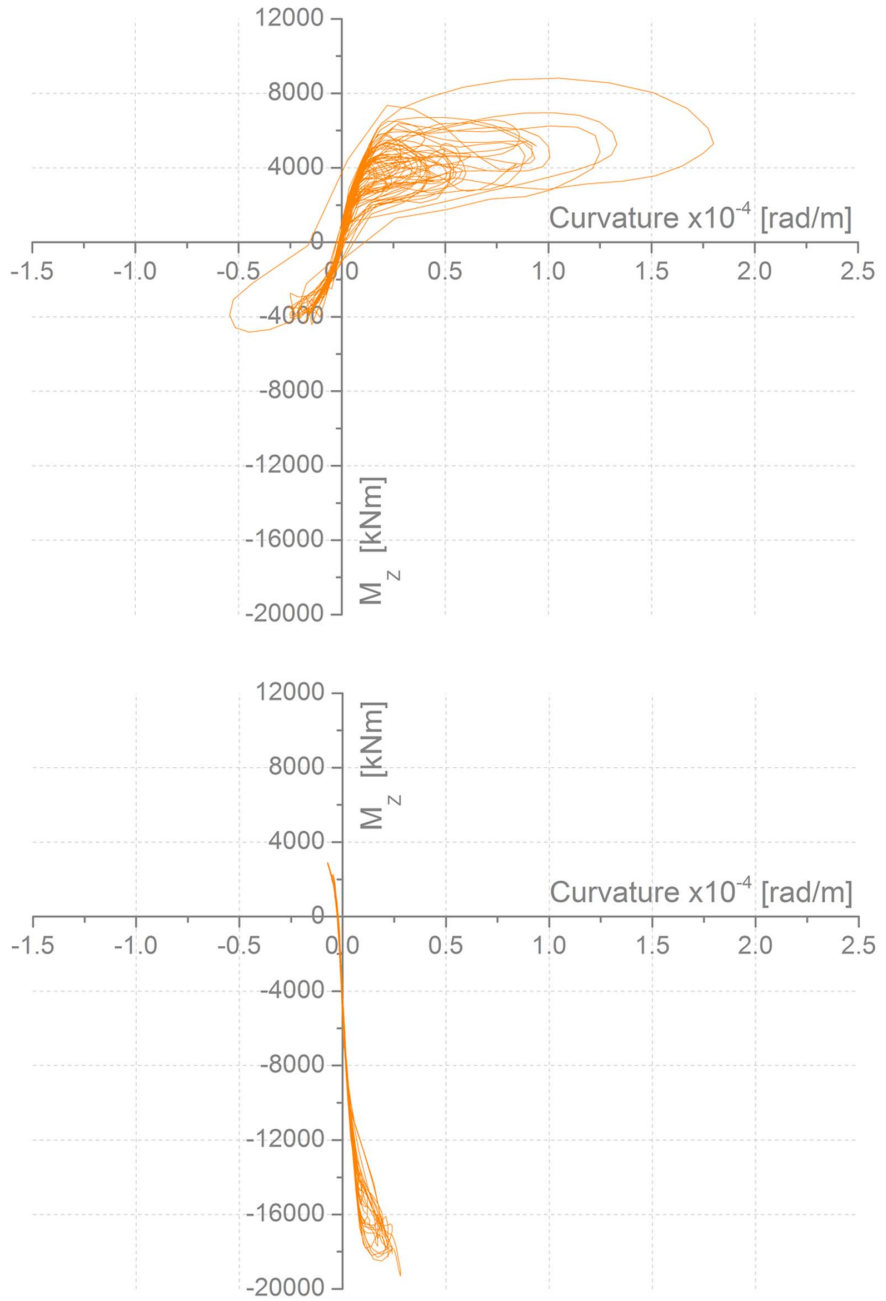

(a)
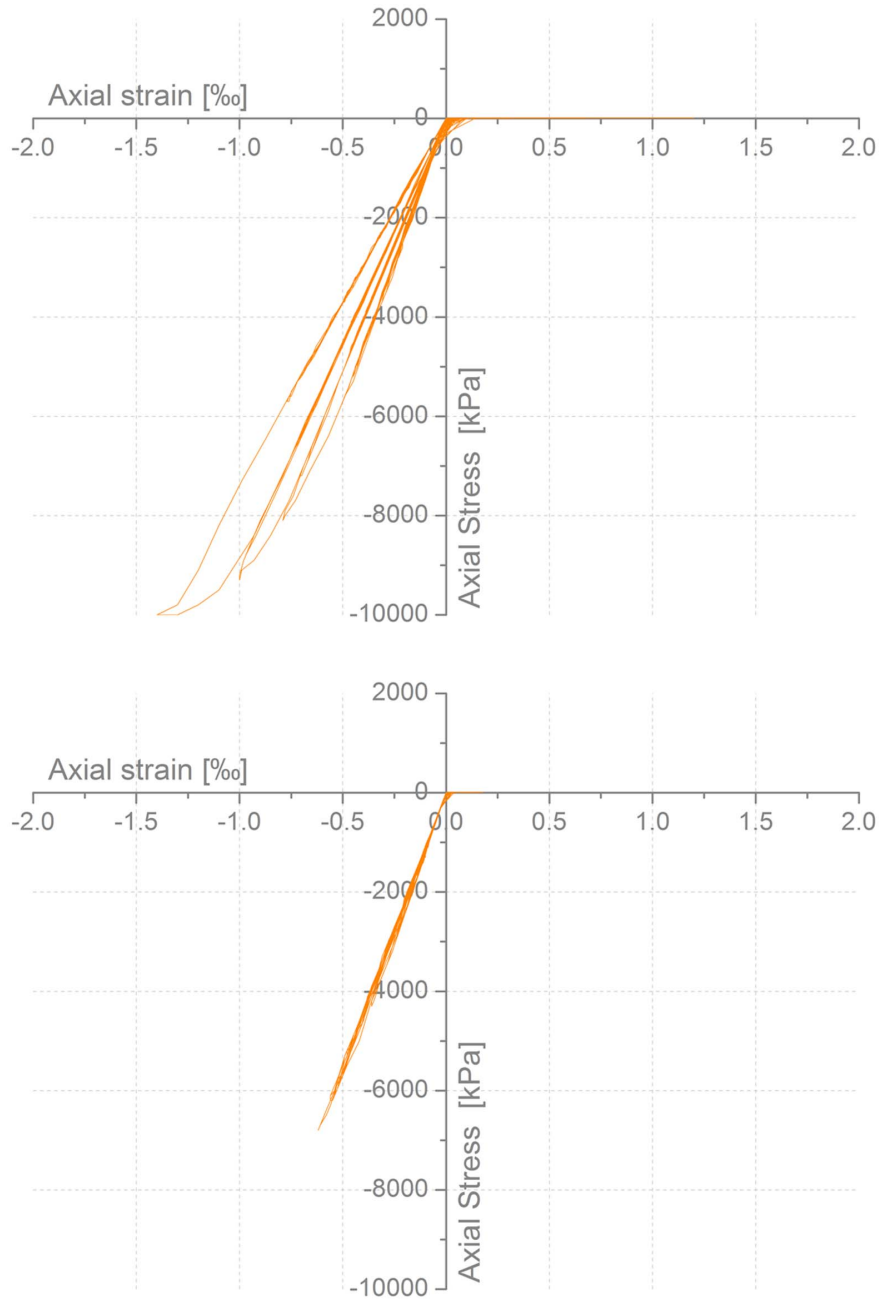

(b)

Fig. 15. Response of the lateral walls, north and south, obtained with seismic input 5000_M82_2: (a) moment-curvature diagrams; and (b) stress-strain curves for the most compressed fibers.

the substructures indicated in Fig. 16 [Zone A: tower + refectory + cloister (west part); Zone B: nave + cloister (central part); and Zone C: transept + chapels + apse + sacristy + cloister (east part)] partially. This is followed by a comparative analysis of the static and dynamic base shear results.

The analysis of the in-plan base shear distribution (Fig. 17) shows that the maximum base shear coefficients (defined as the ratio of the maximum base shear acting on the elastic structure to the total weight of the structure) in Zones $\mathrm{A}$ and $\mathrm{C}$ are about 2-4 times greater than those in Zone B. These results reflect the differing in-plan structural stiffnesses of the church between Zone B (the nave), which is less stiff, and Zones A and C, which are much stiffer; this possibly works as a bracing system to the structure, as the modal analysis seems to confirm. The observable linear correlation between the base shear values and the seismic intensities (PGA) suggests a high average global stiffness of the church and its quite linear global behavior, excepting the Zone $\mathrm{B}$ (nave) that has a residual contribution to the global base shear coefficient.

It is worth noting that the smaller the relative contribution, the greater the return period, due to the damage suffered (Fig. 17). Finally, despite their important role in the structural integrity of the church, the contribution of the nave columns to base shear was found to be insignificant for all seismic scenarios considered.
In order to assess the potential relationship between the static global base shear coefficients $(\beta)$ obtained through uniform pushover analysis as recommended in Lourenço et al. (2011) and the envelope of the global base shear coefficient obtained from the

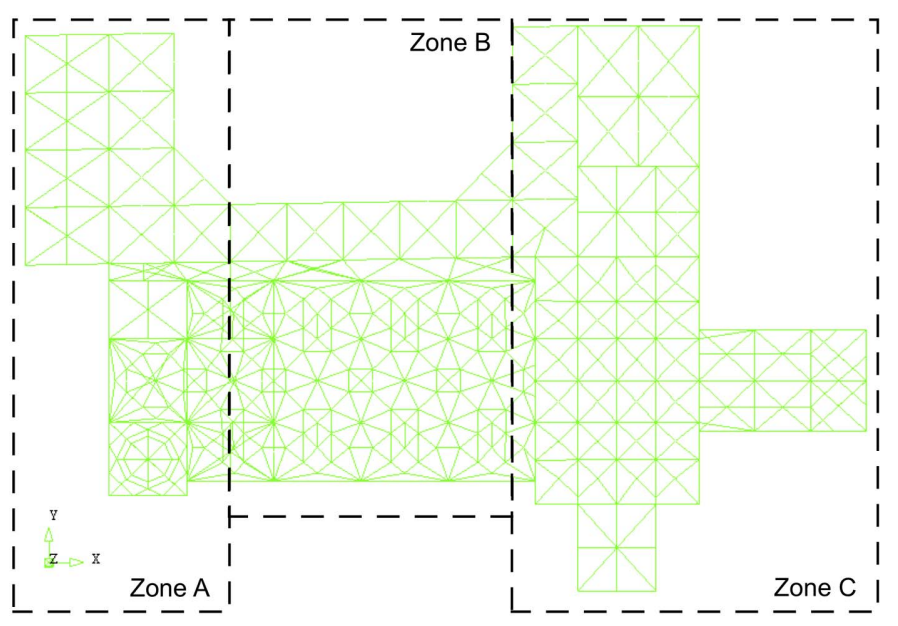

Fig. 16. Plan view of the finite-element model Zones A, B, and C indicated. 


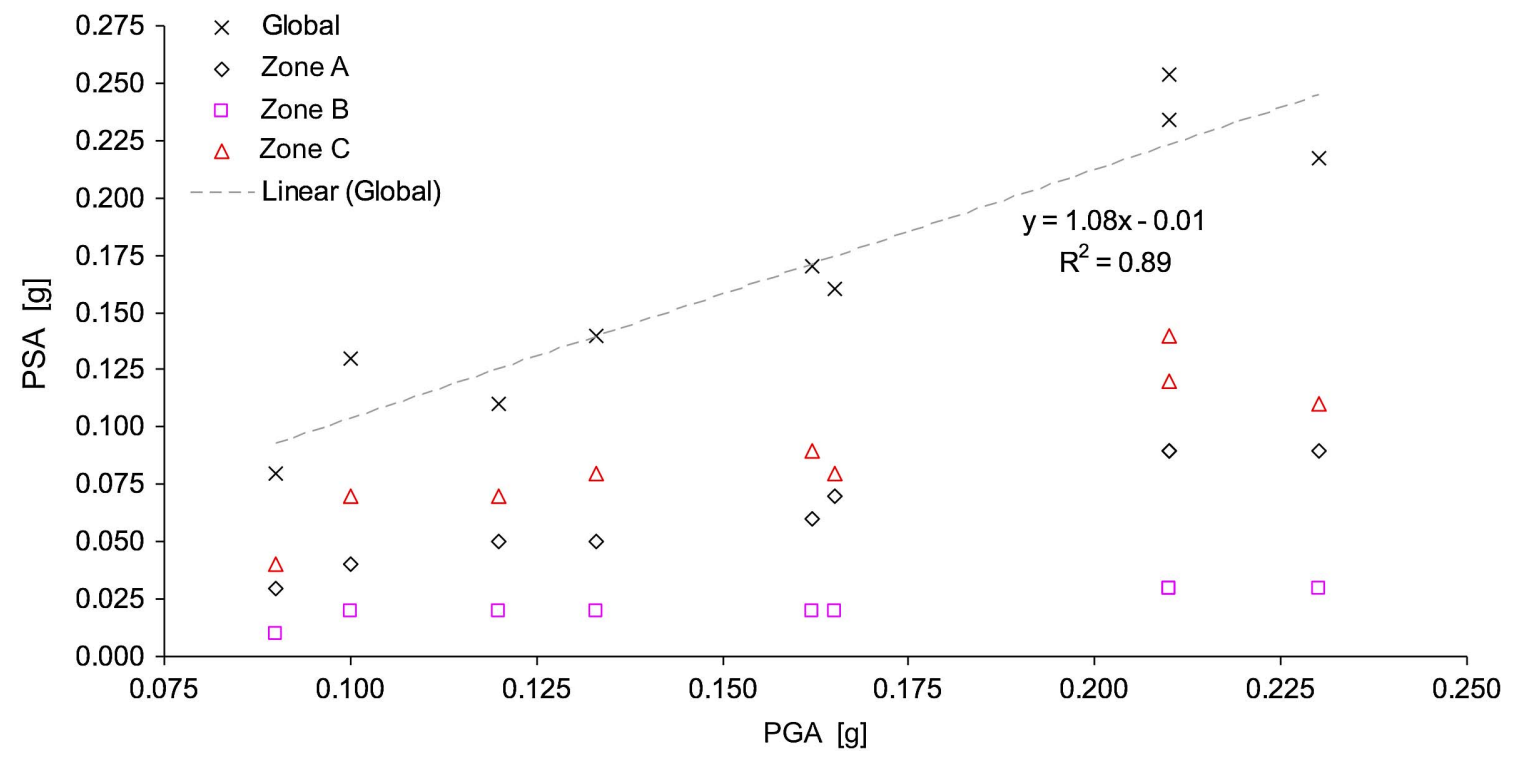

Fig. 17. Base shear coefficients pseudospectral acceleration (PSA) versus peak ground acceleration (PGA) of the seismic inputs used (average maximum values per structural Zones A, B, and C).

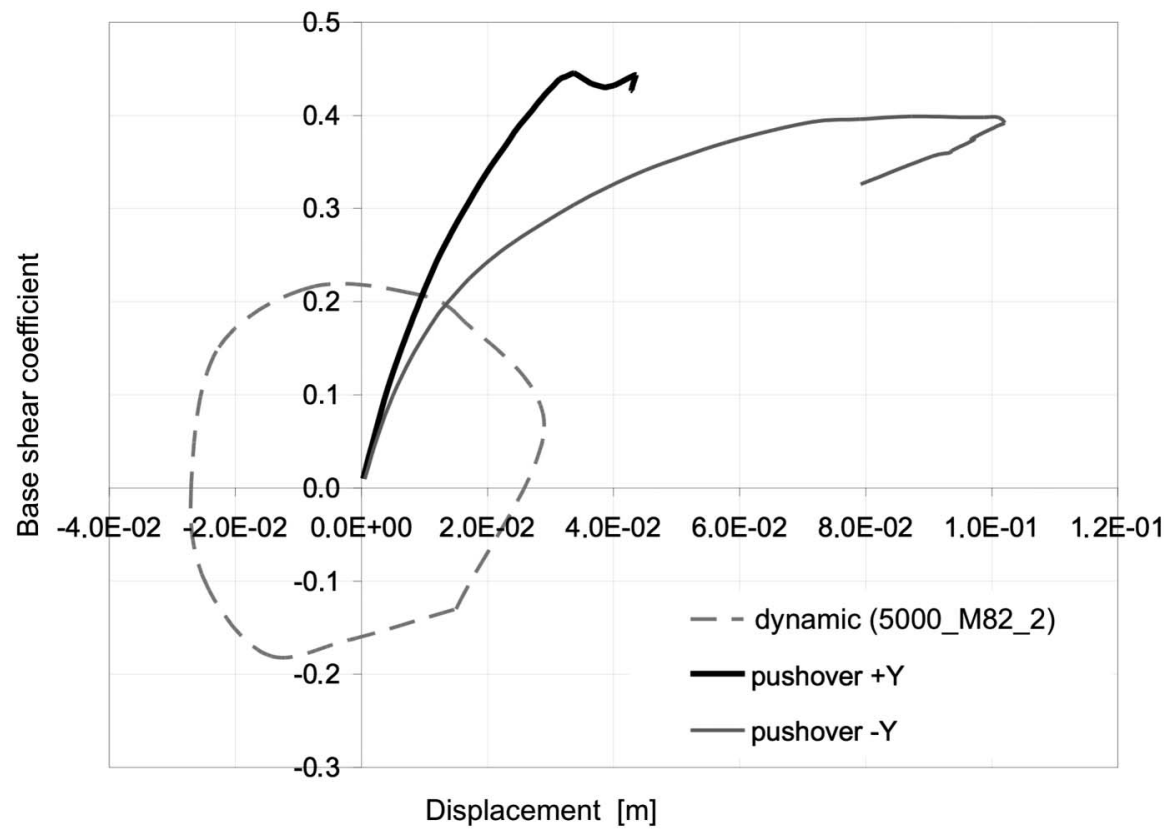

Fig. 18. Envelope of the dynamic base shear versus uniform pushover capacity curves $(+Y,-Y)$.

dynamic analyses (for the 5000_M82_2 seismic input), both results are plotted together in Fig. 18.

A comparison of the outcomes obtained with aforementioned strategies shows that (1) the collapse modes obtained are rather different - the pushover analyses led to the collapse of the columns, the walls, and the vault, whereas only the north column collapsed as a result of the dynamic analyses; (2) the collapse of the north column occurs in both strategies, with a similar configuration; (3) in the pushover analyses, the collapse of the north column has a larger load factor $(0.44 \mathrm{~g})$, while the south column collapse presents a smaller one $(0.40 \mathrm{~g})$; (4) the maximum dynamic global base shear coefficient (equivalent) is approximately half of the static shear coefficients (pushover); and (5) the columns had a residual contribution to the global base shear.
Thus, from Points 1 and 2 it was possible to conclude that pushover analyses were able to only partly identify the seismic vulnerability of the church. Points 3 and 4 suggest that pushover analysis is only partly representative of the dynamic behavior of the church, because its response seems to be highly influenced by dynamic effects not considered in pushover analysis. The lack of consideration of the higher local modes of the nave columns in the structural response is the main reason for this apparent lack of global representativeness. To better understand this phenomenon, the in-plan base shear distribution among Zones $\mathrm{A}, \mathrm{B}$, and $\mathrm{C}$ and the north column was analyzed, considering both static and dynamic approaches (Fig. 19), and some additional interesting conclusions can be drawn: (6) the in-plan base shear distribution is, in percentage, identical in both strategies (about 38\% in Zone A; about $10 \%$ 


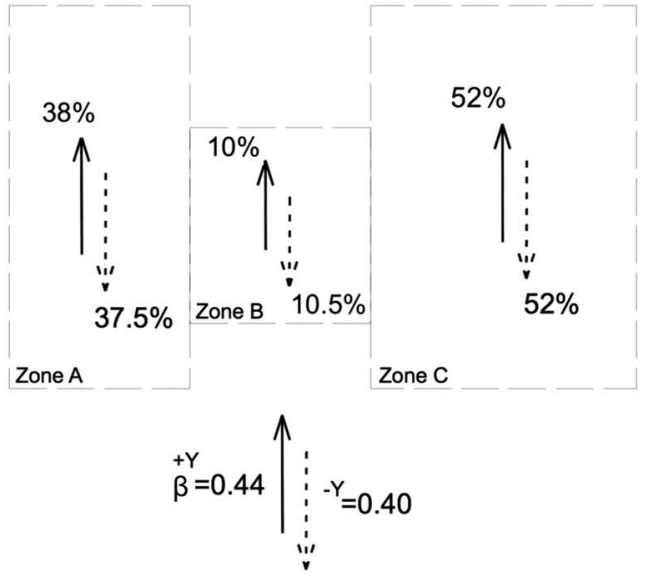

(a)

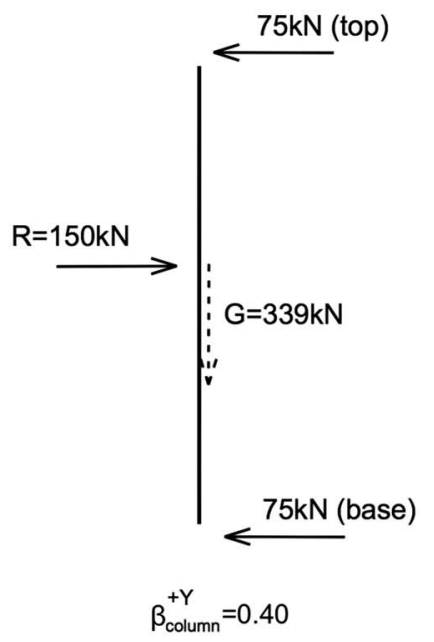

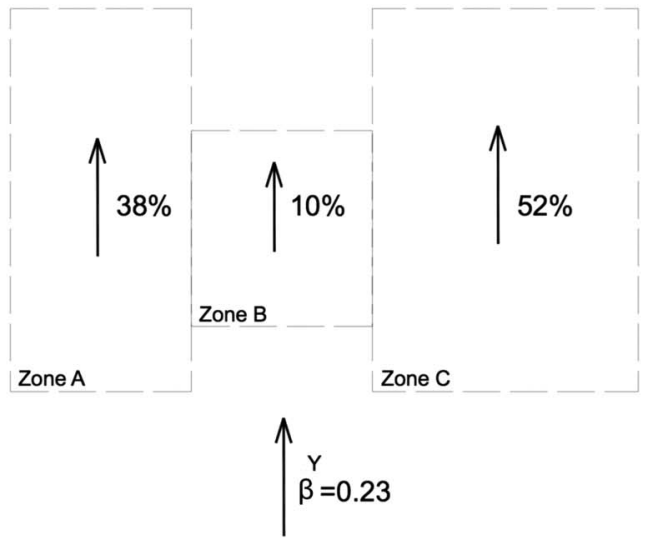

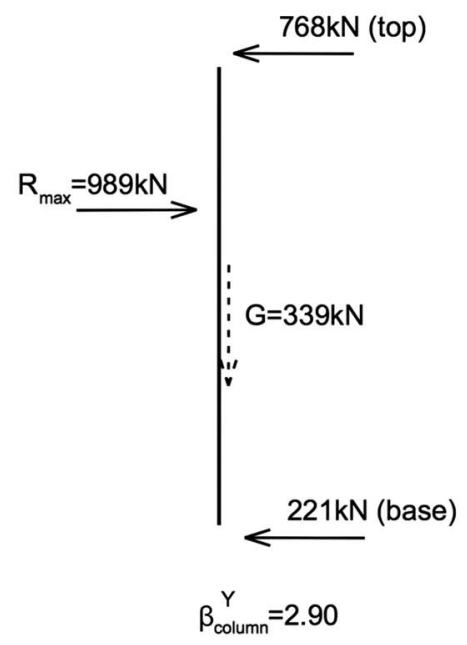

(b)

Fig. 19. Static base shear (uniform pushover, $+Y$ and $-Y$ ) versus envelope of dynamic base shear (seismic input 5000_M82_2): (a) percentage of in-plan distribution; and (b) central north column of the nave (Zone B).

in Zone B; and about 52\% in Zone C); (7) the global base shear coefficient (0.23) obtained from the dynamic analyses considerably underestimates the north column base shear (2.90), resulting in large differences in terms of shear forces at the column (from $150 \mathrm{kN}$ with the pushover analyses to $989 \mathrm{kN}$ with the dynamic analyses); and (8) the global base shear coefficients are not, in any of the strategies, representative of the behavior of the nave columns; this is particularly true of the north columns.

Thus, on the one hand, the contrast found between the values obtained for the global dynamic shear (reaching 0.23) and the dynamic shear coefficients in the north column (equal to 2.90) can be attributed to dynamic effects on the north columns involving the contribution of local higher modes to the response. The high levels of acceleration (of about $3.0 \mathrm{~g}$ ) found in the north column shaft corroborated this interpretation (Fig. 20). On the other hand, the difference between the values of the global dynamic shear $(0.23)$ and global static shear coefficients $(0.44)$ can be interpreted as a result of the reduced representativeness of the pushover analysis for complex historical constructions, as in the present case study.

Complementarily, Peña et al. (2010) underlined the importance and the influence of the lateral load distribution on the results obtained from static analyses (pushover). In this regard, it is plausible that the global representativeness of the static analyses could increase with the use of triangular (or first mode proportional to global translation) pushover. However, the authors do not recommend this for the usual out-of-plane failure analysis of historical constructions [see also Lourenço et al. (2011)].

Based on the foregoing outcomes, it should be underlined that pushover analysis may not be representative of the dynamic behavior of the most critical structural elements of complex historical constructions, even though pushover can be efficient in detecting such structures' main global seismic vulnerabilities.

\section{Postaction Analysis}

In the cases for which no apparent collapse was observed, the numerical simulation of the seismic performance of the church was followed by a postaction eigenvalue analysis using the tangent stiffness of the damaged model, aimed at assessing the earthquake-induced decay in natural frequencies from the original to the damaged model. This type of analysis is not of interest when significant structural damage occurs. Significant damage, even when no collapse is observed, might render the stiffness matrix ill-conditioned with the results of such a modal analysis to be of no value. Fig. 21 shows the frequencies of the 16 first vibration 


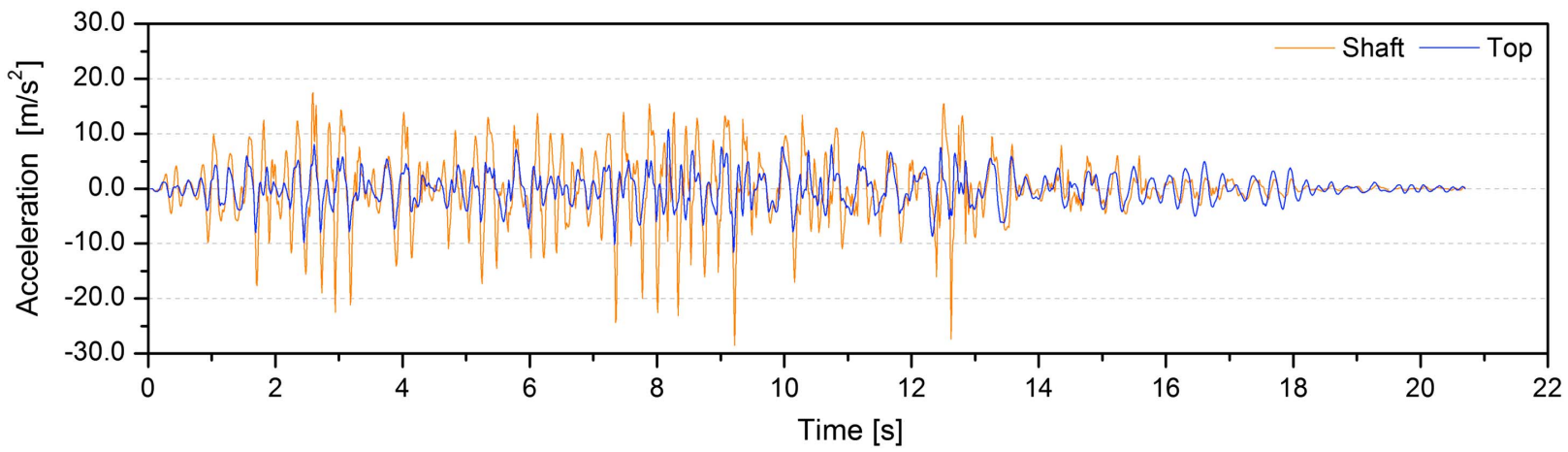

Fig. 20. Time history of accelerations in the north column shaft (at the top and middle sections) for seismic input 5000_M82_2.

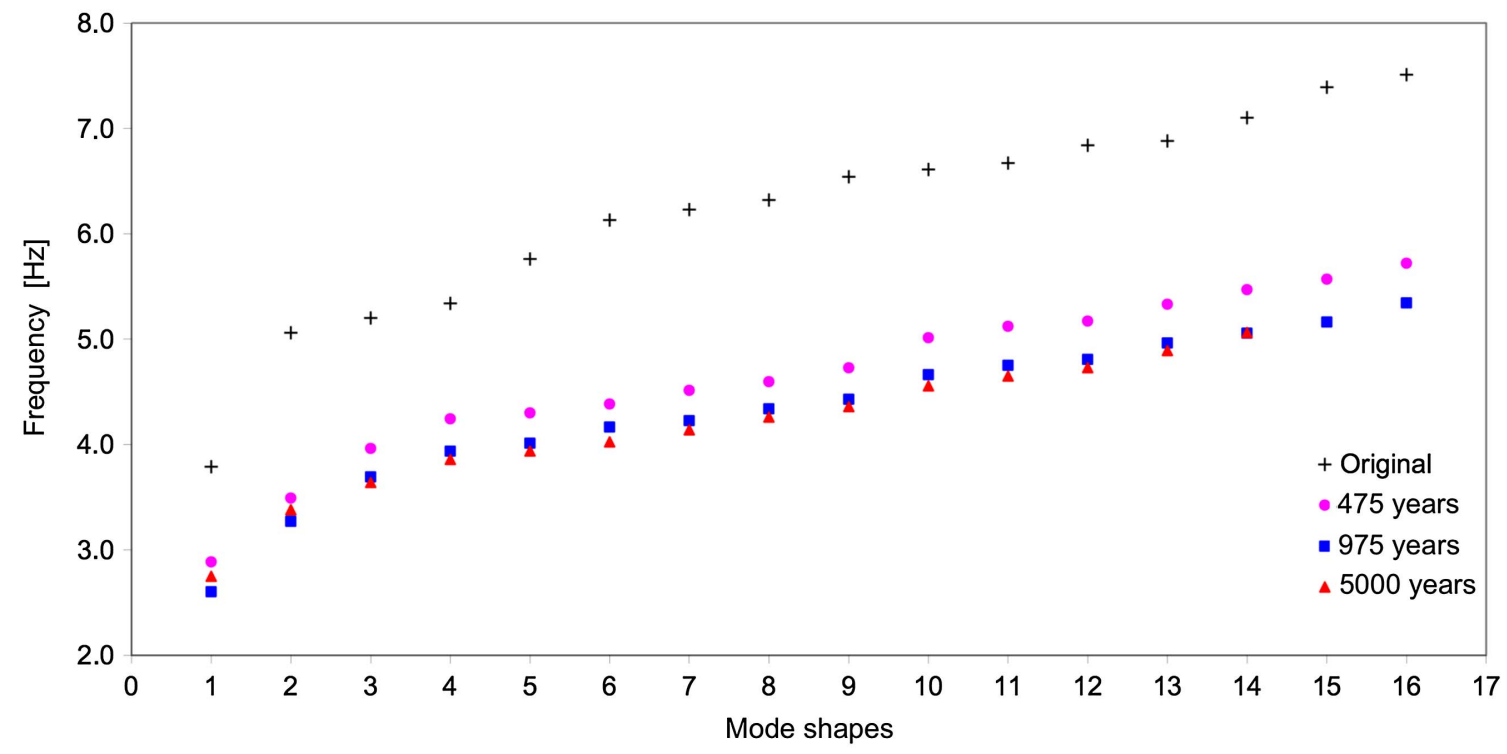

Fig. 21. Modal frequencies of the church, before and after seismic excitations (average values per return period).

modes of the church found for both situations, before and after the seismic excitations for each return period. Some important remarks can be made based on the modal frequency decays, reported in Fig. 21.

First, there is an average and nearly uniform reduction of about $1.5 \mathrm{~Hz}$ in the modal frequencies of the church (i.e., the first 16 numerical frequencies were reduced from $3.8-7.51 \mathrm{~Hz}$ to 2.8-5.3 Hz), suggesting a uniform stiffness reduction due to earthquake-induced damage (essentially, cracking) on the church.

Second, despite the different characteristics of the seismic inputs (both in duration and PGA), the reduced contrast found in the average modal frequencies of the church may indicate that the resulting structural damage is more associated with the frequency content of the adopted accelerograms rather than with their peak ground acceleration or duration.

Third, in relative terms, the greatest levels of damage occur for the lowest severe scenarios, with a return period of 475 years.

The similarity between the frequency band of the resonant modes of the nave (columns and vault) (found to be between 3.8 and $7.5 \mathrm{~Hz}$ ) and the dominant spectral content of the seismic signals used (found to be between 3 and $7.5 \mathrm{~Hz}$ ) seem to justify the special incidence of structural damage on the main nave (columns and vault) and an approximately uniform distribution for the different seismic hazard scenarios.
Finally, because the initial Rayleigh damping ratio $(1.5 \%)$ adopted was associated with the first $(3.8 \mathrm{~Hz})$ and second $(5.06 \mathrm{~Hz})$ global frequencies of the nave, it is expected that the Rayleigh damping ratio after the model was damaged is under $1.62 \%$ for the final range of frequencies (found to be between 2.8 and $5.3 \mathrm{~Hz}$ ).

\section{Conclusions}

This paper presents and discusses the main results obtained from an incremental nonlinear dynamic analysis of the church of Santa Maria de Belém, considering three different seismic hazard scenarios with increasing severity, associated with return periods of 475 , 975, and 5,000 years. This work continues previous studies reported in Masciotta et al. (2016); that work analyzed the linear and nonlinear static response of the church.

The results obtained for return periods of 475 and 975 years show that the church is expected to suffer extensive cracking, however, no partial or global ruin is predicted. For a 5,000-year return period, some potential partial collapses were identified involving the north columns of the nave. The south tower belfry appears to be one of the most vulnerable elements of the church, having the potential to overturn. 
Regardless of the scenarios, an asymmetric and clear frame-type behavior between the walls and columns was found in the transverse arcades of the nave, which led to high variations in the axial load of the columns. Even so, the level of compressive stress was moderate, and, as a result, the potential collapse of the columns may be determined by eccentric compression.

In terms of deformability, drift values below $0.5 \%$ were observed in the central arcade for all seismic scenarios; even during the precollapse phase the nonlinear geometric effects presented a low contribution to collapse onset.

With regard to the base shear analysis of the church, a comparison between the static and dynamic results allows the authors to state that despite the major contribution of the nave columns to the structural integrity of the church, their contribution to the global base shear is only residual; static pushover analyses, although efficient in detecting the main seismic vulnerabilities of the church, were not representative of the dynamic behavior of some important substructures (such as the nave columns).

The results of the modal analyses performed after seismic excitation revealed a residual average modal stiffness of about half of the initial modal stiffness of the church, showing that the most of the damage, especially the damage concentrated in the nave, was associated with the 475-year return period scenario and was mainly due to the excitation frequency content.

Overall, the base shear analysis presented in this paper provides a practical demonstration that pushover strategies should be used with great care when dealing with historical buildings, because possible dynamic effects involving the contribution of higher order modes can guide the dynamic response in a manner rather different from the static response.

The postaction eigenvalue value analysis that was performed provides a practical demonstration of a useful way to assess the level of earthquake-induced damage, considering the decay of the natural frequencies before and after seismic excitation.

Finally, this work also underlines the fact that the numerical seismic assessment of large historical constructions is still a complex field; therefore, research on this subject should be encouraged.

\section{Acknowledgments}

This work was partly financed by European Regional Development Fund (ERDF) funds through the Operational Programme Competitiveness Factors (COMPETE) and by national funds through the Foundation for Science and Technology (FCT) within the scope of project POCI-01-0145-FEDER-007633. The authors are also grateful to three anonymous reviewers whose comments significantly improved the clarity of the paper.

\section{References}

Araujo, A. S., P. B. Lourenço, D. V. Oliveira, and J. Leite. 2012. "Seismic assessment of St James church by means of pushover analysis-Before and after the New Zealand earthquake." Open Civ. Eng. J. 6 (1): 160-172. https://doi.org/10.2174/1874149501206010160.

Betti, M., L. Galano, and A. Vignoli. 2015. "Time-history seismic analysis of masonry buildings: A comparison between two non-linear modelling approaches." Buildings 5 (2): 597-621. https://doi.org/10.3390 /buildings5020597.

Betti, M., M. Orlando, and A. Vignoli. 2011. "Static behaviour of an Italian medieval castle: Damage assessment by numerical modelling." Comput. Struct. 89 (21-22): 1956-1970. https://doi.org/10.1016/j.compstruc .2011.05.022

Betti, M., and A. Vignoli. 2011. "Numerical assessment of the static and seismic behaviour of the basilica of Santa Maria all'Impruneta (Italy)."
Constr. Build. Mater. 25 (12): 4308-4324. https://doi.org/10.1016/j .conbuildmat.2010.12.028.

Carvalho, A., A. Campos Costa, and C. S. Oliveira. 2004. "Modelos estocásticos com ruptura progressiva de falhas para a caracterização da acção sísmica." In Aplicação ao sismo de Lisboa de 1 de Novembro de 1755, 281-290. Guimarães, Portugal: Univ. of Minho.

Carvalho, A., A. Campos Costa, and C. S. Oliveira. 2009. "A finite-fault modeling of the 1755 Lisbon earthquake sources." In The 1755 Lisbon earthquake: Revisited, geotechnical, geological, and earthquake engineering, 433-454. Dordrecht, Netherlands: Springer.

D'Ayala, D. 2013. "Assessing the seismic vulnerability of masonry buildings." In Handbook of seismic risk analysis and management of civil infrastructure systems, 334-365. Amsterdam, Netherlands: Elsevier.

DPCM (Decree of the President of the Council of Ministers). 2011. Linee guida per la valutazione e la riduzione del rischio sismico del patrimonio culturale con riferimento alle Norme tecniche delle costruzioni di cui al decreto del Ministero delle Infrastrutture e dei trasporti del 14 gennaio; 2008. Rome: Italian Government.

Ferreira, T. M., A. A. Costa, A. Arêde, A. Gomes, and A. Costa. 2015a. "Experimental characterization of the out-of-plane performance of regular stone masonry walls, including test setups and axial load influence.” Bull. Earthquake Eng. 13 (9): 2667-2692. https://doi.org/10 .1007/s10518-015-9742-1.

Ferreira, T. M., A. A. Costa, and A. Costa. 2015b. "Analysis of the out-of-plane seismic behavior of unreinforced masonry: A literature review." Int. J. Archit. Heritage 9 (8): 949-972. https://doi.org/10.1080 /15583058.2014.885996.

Gattulli, V., E. Antonacci, and F. Vestroni. 2013. "Field observations and failure analysis of the Basilica S. Maria di Collemaggio after the 2009 L'Aquila earthquake." Eng. Fail. Anal. 34 (Dec): 715-734. https://doi .org/10.1016/j.engfailanal.2013.01.020.

Hilber, H. M., T. J. R. Hughes, and R. L. Taylor. 1977. "Improved numerical dissipation for time integration algorithms in structural dynamics." Earthquake Eng. Struct. Dyn. 5 (3): 283-292. https://doi.org/10.1002 leqe. 4290050306.

Lagomarsino, S., and S. Resemini. 2009. "The assessment of damage limitation state in the seismic analysis of monumental buildings." Earthquake Spectra 25 (2): 323-346. https://doi.org/10.1193/1.3110242.

Lourenço, P. B. 2002. "Computations on historic masonry structures." Prog. Struct. Eng. Mater. 4 (3): 301-319. https://doi.org/10.1002/pse .120 .

Lourenço, P. B., K. J. Krakowiak, F. M. Fernandes, and L. F. Ramos. 2007. "Failure analysis of monastery of Jerónimos, Lisbon: How to learn from sophisticated numerical models." Eng. Fail. Anal. 14 (2): 280-300. https://doi.org/10.1016/j.engfailanal.2006.02.002.

Lourenço, P. B., N. Mendes, L. F. Ramos, and D. V. Oliveira. 2011. "Analysis of masonry structures without box behavior." Int. J. Archit. Heritage 5 (4-5): 369-382. https://doi.org/10.1080/15583058.2010.528824.

Maio, R., and G. Tsionis. 2016. Seismic fragility curves for the European building stock: Review and evaluation of existing fragility curves-EU Science hub-European commission. JRC Technical Report. Ispra, Italy: Joint Research Centre.

Masciotta, M.-G., J. Roque, L. F. Ramos, and P. B. Lourenço. 2016. "A multidisciplinary approach to assess the health state of heritage structures: The case study of the church of monastery of Jerónimos in Lisbon." Constr. Build. Mater. 116 (Jul): 169-187. https://doi.org/10 .1016/j.conbuildmat.2016.04.146.

Milani, G. 2013. "Lesson learned after the Emilia-Romagna, Italy, 20-29 May 2012 earthquakes: A limit analysis insight on three masonry churches." Eng. Fail. Anal. 34 (Dec): 761-778. https://doi.org/10 .1016/j.engfailanal.2013.01.001

Milani, G., and M. Valente. 2015a. "Comparative pushover and limit analyses on seven masonry churches damaged by the 2012 Emilia-Romagna (Italy) seismic events: Possibilities of non-linear finite elements compared with pre-assigned failure mechanisms." Eng. Fail. Anal. 47 (Jan): 129-161. https://doi.org/10.1016/j.engfailanal.2014.09.016.

Milani, G., and M. Valente. 2015b. "Failure analysis of seven masonry churches severely damaged during the 2012 Emilia-Romagna (Italy) earthquake: Non-linear dynamic analyses vs conventional static 
approaches.” Eng. Fail. Anal. 54 (Aug): 13-56. https://doi.org/10.1016 /j.engfailanal.2015.03.016.

Milani, G., and G. Venturini. 2011. "Automatic fragility curve evaluation of masonry churches accounting for partial collapses by means of 3D FE homogenized limit analysis." Comput. Struct. 89 (17-18): 1628-1648. https://doi.org/10.1016/j.compstruc.2011.04.014.

Milani, G., and G. Venturini. 2013. "Safety assessment of four masonry churches by a plate and shell FE nonlinear approach." J. Perform. Constr. Facil. 27 (1): 27-42. https://doi.org/10.1061/(ASCE)CF.1943 $-5509.0000321$.

Peña, F., P. B. Lourenço, N. Mendes, and D. V. Oliveira. 2010. "Numerical models for the seismic assessment of an old masonry tower." Eng. Struct. 32 (5): 1466-1478. https://doi.org/10.1016/j.engstruct.2010.01.027.

Ramos, L. F., L. Marques, P. B. Lourenço, G. De Roeck, A. Campos Costa, and J. Roque. 2010. "Monitoring historical masonry structures with operational modal analysis: Two case studies." Mech. Syst. Signal
Process. 24 (5): 1291-1305. https://doi.org/10.1016/j.ymssp.2010.01 .011 .

Roque, J. 2010. "Metodologia integrada para avaliação e mitigação da vulnerabilidade sísmica das construções históricas em alvenaria: A Igreja dos Jerónimos como caso de estudo.” Ph.D. thesis, Dept. of Civil Engineering, Univ. of Minho.

Scotta, R., R. Vitaliani, A. Saetta, E. Oñate, and A. Hanganu. 2001. "A scalar damage model with a shear retention factor for the analysis of reinforced concrete structures: Theory and validation." Comput. Struct. 79 (7): 737-755. https://doi.org/10.1016/S0045-7949(00)00178-4.

Sousa, M. L. 2006. "Risco sísmico em Portugal continental." Ph.D. thesis, Dept. of Civil Engineering, Technical Univ. of Lisbon.

Valente, M., and G. Milani. 2016. "Seismic assessment of historical masonry towers by means of simplified approaches and standard FEM." Constr. Build. Mater. 108 (Apr): 74-104. https://doi.org/10 .1016/j.conbuildmat.2016.01.025. 